\title{
Multidimensional rehabilitation programmes for adult cancer survivors (Review)
}

Scott DA, Mills M, Black A, Cantwell M, Campbell A, Cardwell CR, Porter S, Donnelly M

Scott DA, Mills M, Black A, Cantwell M, Campbell A, Cardwell CR, Porter S, Donnelly M.

Multidimensional rehabilitation programmes for adult cancer survivors.

Cochrane Database of Systematic Reviews 2013, Issue 3. Art. No.: CD007730.

DOI: 10.1002/14651858.CD007730.pub2.

www.cochranelibrary.com 
TABLE OF CONTENTS

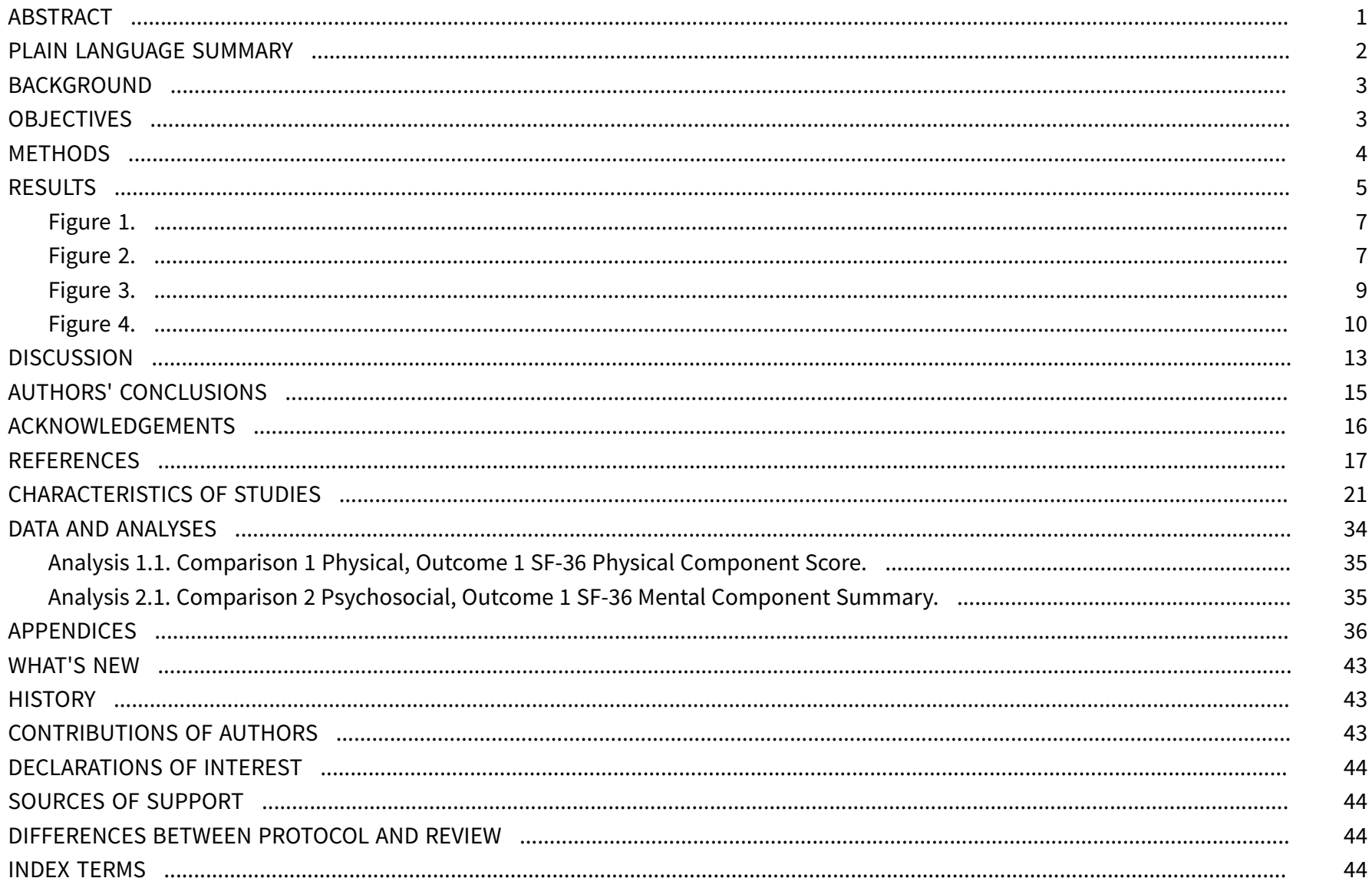


[Intervention Review]

\section{Multidimensional rehabilitation programmes for adult cancer survivors}

David A Scott ${ }^{1}$, Moyra Mills², Amanda Black ${ }^{3}$, Marie Cantwell ${ }^{4}$, Anna Campbell ${ }^{5}$, Chris R Cardwell ${ }^{4}$, Sam Porter 6 , Michael Donnelly 4

${ }^{1}$ Centre for Health Improvement, Queen's University Belfast, Belfast, UK. ${ }^{2}$ Northern Health and Social Care Trust, Antrim, UK. ${ }^{3}$ Division of Cancer Epidemiology and Genetics, National Cancer Institute, Bethesda, MD, USA. ${ }^{4}$ Centre for Public Health, Queen's University Belfast, Belfast, UK. ${ }^{5}$ University of Surrey, Guildford, UK. ${ }^{6}$ School of Nursing and Midwifery, Queen's University Belfast, Belfast, UK

Contact: David A Scott, Centre for Health Improvement, Queen's University Belfast, Medical Biology Centre, 97 Lisburn Road, Belfast, Northern Ireland, BT9 7BL, UK. david.scott@qub.ac.uk.

Editorial group: Cochrane Gynaecological, Neuro-oncology and Orphan Cancer Group.

Publication status and date: Edited (no change to conclusions), published in Issue 9, 2016.

Citation: Scott DA, Mills M, Black A, Cantwell M, Campbell A, Cardwell CR, Porter S, Donnelly M. Multidimensional rehabilitation programmes for adult cancer survivors. Cochrane Database of Systematic Reviews 2013, Issue 3. Art. No.: CD007730. DOI:

10.1002/14651858.CD007730.pub2.

Copyright @ 2016 The Cochrane Collaboration. Published by John Wiley \& Sons, Ltd.

\section{A B S T R A C T}

\section{Background}

Multidimensional rehabilitation programmes (MDRPs) have developed in response to the growing number of people living with and surviving cancer. MDRPs comprise a physical component and a psychosocial component. Studies of the effectiveness of these programmes have not been reviewed and synthesised.

\section{Objectives}

To conduct a systematic review of studies examining the effectiveness of MDRPs in terms of maintaining or improving the physical and psychosocial well-being of adult cancer survivors.

\section{Search methods}

We conducted electronic searches in the Cochrane Central Register of Controlled Trials (CENTRAL), MEDLINE, EMBASE, CINAHL and PsychINFO up to February 2012.

\section{Selection criteria}

Selection criteria focused on randomised controlled trials (RCTs) of multidimensional interventions for adult cancer survivors. Interventions had to include a physical component and a psychosocial component and to have been carried out on two or more occasions following completion of primary cancer treatment. Outcomes had to be assessed using validated measures of physical health and psychosocial well-being. Non-English language papers were included.

\section{Data collection and analysis}

Pairs of review authors independently selected trials, rated their methodological quality and extracted relevant data. Although metaanalyses of primary and secondary endpoints were planned there was a high level of study heterogeneity and only one common outcome measure (SF-36) could be statistically synthesised. In addition, we conducted a narrative analysis of interventions, particularly in terms of inspecting and identifying intervention components, grouping or categorising interventions and examining potential common links and outcomes.

\section{Main results}

Twelve RCTs (comprising 1669 participants) met the eligibility criteria. We judged five studies to have a moderate risk of bias and assessed the remaining seven as having a high risk of bias. It was possible to include SF-36 physical health component scores from five studies in a meta-analysis. Participating in a MDRP was associated with an increase in SF-36 physical health component scores (mean difference 
(MD) 2.22, 95\% confidence interval $(\mathrm{Cl}) 0.12$ to $4.31, \mathrm{P}=0.04)$. The findings from the narrative analysis suggested that MDRPs with a single domain or outcome focus appeared to be more successful than programmes with multiple aims. In addition, programmes that comprised participants with different types of cancer compared to cancer site-specific programmes were more likely to show positive improvements in physical outcomes. The most effective mode of service delivery appeared to be face-to-face contact supplemented with at least one follow-up telephone call. There was no evidence to indicate that MDRPs which lasted longer than six months improved outcomes beyond the level attained at six months. In addition, there was no evidence to suggest that services were more effective if they were delivered by a particular type of health professional.

\section{Authors' conclusions}

There is some evidence to support the effectiveness of brief, focused MDRPs for cancer survivors. Rigorous and methodologically sound clinical trials that include an economic analysis are required.

\section{PLAIN LANGUAGE SUMMARY}

\section{Multidimensional rehabilitation programmes for adult cancer survivors}

Due to improvements in detection, treatment and care an increasing number of patients are living with or surviving cancer. However, patients who survive cancer may experience a range of physical and emotional symptoms which impact on their health and quality of life. Physical symptoms may include fatigue, reduced muscle strength and weight gain, while emotional symptoms may include, for example, anxiety and depression. Rehabilitation programmes have been developed to address these symptoms and problems and to help survivors have a better quality of life. Some rehabilitation programmes attempt to help people overcome difficulties associated with either physical or emotional symptoms whilst other programmes - multidimensional rehabilitation programmes (MDRPs) - try to address physical and emotional symptoms together. This review has collected and examined the best available research to assess the nature and degree to which MDRPs reduce physical and emotional problems and improve the health-related quality of life of adult cancer survivors.

We identified 12 studies which were suitable for use in the review. However, each study had some problems in the way that it was carried out. These problems make it difficult to be certain about the usefulness of MDRPs. Overall, the reviewed articles suggest that MDRPs are more likely to help patients cope with their physical needs than their emotional needs. MDRPs which looked at one specific behaviour area, such as diet, physical activity or stress, appeared to be more helpful for patients than programmes which attempted to address several different behaviours. Successful MDRPs usually involved face-to-face contact between a patient and a health professional (usually a nurse or physical therapist) and included at least one follow-up phone call. Programmes which took place over longer time periods (more than six months), or which were delivered by a specific type of health professional, or were delivered to a single cancer site were not more successful than brief, focused MDRPs delivered to mixed groups of cancer patients. 


\section{B A C K G R O U N D}

\section{Description of the condition}

Advances in the early detection of cancer, improved treatment regimes and an ageing population have resulted in an increase in the number of people living with and surviving cancer. Cancer Research Statistics (CRUK 2008) indicate that the average five-year survival rate for all cancers in the UK is 50\%, with survival rates for some cancers being as high as $87 \%$ (malignant melanoma) and $96 \%$ (testicular cancer). Increasingly cancer is considered to be a chronic or long-term condition for many patients.

Although research on cancer survivorship has increased considerably, there is a lack of consensus about the definition of a 'survivor'. In the US, the term encompasses the entire experience of living with, through and beyond a diagnosis of cancer and includes family members, friends and caregivers affected by the experience ( $\mathrm{NCl} 2004)$. The definition that is used in this review is taken from the UK Cancer Reform Strategy 2007 which describes a survivor as someone who has completed initial treatment and has no apparent evidence of active disease, or is living with progressive disease but is not in the terminal phase of their illness, or someone who has had cancer in the past.

The increasing number of survivors presents a challenge for cancer services. People surviving or living with cancer may experience a variety of short and long-term physical and psychosocial adverse effects which may be directly related to their disease or to treatment (Aziz 2003). Common physical issues include fatigue, reduced physical and cognitive capacity, changes in sexual activity (Schroevers 2006) and medical problems such as osteoporosis, thyroid, heart and lung conditions (Schultz 2003). Psychosocial problems are emotional or mental health issues that may be caused by negative life experiences or be due to maladjusted behavioural and cognitive processes. The type of psychosocial problems associated with cancer include anxiety, depression, low self esteem and fears of recurrence and death (Jefford 2008). Indeed, international studies have shown rates of emotional distress in cancer patients ranging from 35\% to 45\% (Bultz 2008; Galway 2012). The combined effect of physical and psychosocial problems may give rise to societal and interpersonal issues including lifestyle changes and the disruption of home and family roles (Aziz 2002). Support and reassurance from healthcare staff tends to be more accessible at the time of diagnosis and during treatment. However, following completion of treatment many patients report feeling isolated or abandoned (Cardy 2006; Jefford 2008). The importance of providing ongoing personalised information and support relating to past, present and possible future issues has been identified as an essential component of care for this patient group (Jefford 2008).

There is now widespread recognition of the importance of addressing the long-term needs of cancer survivors. In the US, a National Coalition for Cancer Survivorship (NCCS 2009) has been created and in conjunction with other leading medical groups NCCS is producing evidence-based guidelines and implementing cancer survivorship care plans (Hewitt 2006). Meanwhile, in the UK the Cancer Reform Strategy 2007 highlighted that survivors of cancer should be provided with assistance to resume as normal a life as is possible. A National Cancer Survivorship Initiative was established to consider a range of approaches to survivorship care and to identify ways in which these approaches could be tailored to meet the needs of patients. Some of the suggested approaches include education, self care, psychological and spiritual support, nutritional advice and the provision of rehabilitation programmes.

\section{Description of the intervention}

Rehabilitation has been defined as "a planned program in which the person progresses towards, or maintains the maximum degree of physical and psychological independence of which they are capable" (Roper 1987). Rehabilitation programmes have been shown to be beneficial for patients with other chronic diseases such as heart disease (Jolliffe 2001), multiple sclerosis (Khan 2008) and chronic obstructive pulmonary disease (Lacasse 2006). Owing to the success of these programmes, cancer-specific rehabilitation programmes have been developed in various countries including America, Australia and the Netherlands. Previous reviews have examined programmes which comprise a physical component such as exercise (Cramp 2012; Fong 2012; Markes 2006; Speck 2010; Spence 2010) or a psychosocial component such as psychoeducation or cognitive behavioural therapy (CBT) (Edwards 2008; Fors 2011).

The primary focus of physical rehabilitation programmes is to restore physical functioning and help survivors overcome role limitations caused by their illness and treatment. Physical interventions such as exercise or dietary change are believed to benefit cancer patients by improving functional capacity, muscle wastage and may help alleviate cancer-related fatigue (van Weert 2005). Psychosocial interventions such as mindfulness training or CBT aim to improve psychological functioning and alleviate mental health difficulties associated with the completion of cancer treatment (Fawzy 1993). Exercise appears to have longerterm beneficial outcomes for cancer patients whilst psychosocial programmes appear to exert only short-term impacts (van Weert 2005).

\section{How the intervention might work}

It has been proposed that multidimensional rehabilitation programmes (MDRPs) which include physical and psychosocial components provide people with the skills to manage their own care and lead to improvements in knowledge, coping behaviour, self efficacy and enhanced quality of life (QoL) (Corner 2007). Consequently, physical and psychosocial interventions have been combined within one programme for patients with a range of chronic illnesses (Jolliffe 2001; Khan 2008; Lacasse 2006).

\section{Why it is important to do this review}

It is unclear whether or not multidimensional programmes represent an effective intervention for cancer survivors (van Weert 2005). Thus, the aim of this review was to evaluate the effectiveness and added value of MDRPs for cancer survivors in order to facilitate the development of evidence-based cancer rehabilitation programmes. This review collates and synthesises systematically the best available research evidence on the effectiveness of MDRPs for adult cancer survivors.

\section{OB JECTIVES}

To conduct a systematic review of of studies examining the effectiveness of MDRPs in terms of maintaining or improving the physical and psychosocial well-being of adult cancer survivors. 
The review evaluated the nature and extent to which:

- professionally led MDRPs achieved better outcomes than standard services for cancer survivors;

- rehabilitation programmes impacted on different domains (e.g. psychosocial health, physical functioning);

- different modes of delivery and different settings influenced outcomes;

- the number, duration and intensity of rehabilitation sessions was related to change in measured outcomes.

\section{METHOD S}

\section{Criteria for considering studies for this review}

\section{Types of studies}

Randomised controlled trials (RCTs) including quasi-RCTs of multidimensional interventions for adult cancer survivors.

\section{Types of participants}

Adults aged 18 and over who were diagnosed with any type or stage of cancer and who completed their primary active treatment regime, e.g. surgery, chemotherapy or radiotherapy.

\section{Types of interventions}

Interventions comprised a physical component (e.g. exercise, dietary regime) and a psychosocial component (e.g. counselling, cognitive behaviour therapy, psycho-educational strategies), and were delivered as individual or group sessions, in person or via telephone or the internet, in any setting (e.g. home, community or clinic-based). Only interventions that involved two or more interactive sessions and were delivered by a healthcare professional such as a doctor, nurse or physical therapist were included. The review excluded programmes that were delivered by people who were not professionally qualified healthcare professionals and programmes which focused on 'return to work' as a primary outcome as these programmes have been reviewed elsewhere (De Boer 2011).

Eligible studies included control groups (compared to cancer survivors) that did not receive an intervention or that received 'standard care', a lower-level intensity programme, a different mode of administration or different delivery settings.

\section{Types of outcome measures}

\section{Primary outcomes}

Primary endpoints included the following.

- Physical outcomes included changes in physical or functional status (e.g. exercise tolerance, physical fitness, weight control, dietary intake) or symptom control (e.g. pain, fatigue).

- Psychosocial outcomes included measures of quality of life (QoL), self efficacy, anxiety or depression. These measures were assessed using established validated scales (e.g. European Organisation for Research and Treatment in Cancer Quality of Life measure (EORTC), Functional Assessment of Cancer Therapy measure (FACT), Short Form-36 measure (SF-36), Beck Depression Inventory or Hospital Anxiety and Depression Scale (HADS)).

\section{Secondary outcomes}

- Patient adherence and satisfaction with rehabilitation programmes.

- Adverse outcomes, e.g. mortality or morbidity directly related to the programmes or programme attrition.

\section{Search methods for identification of studies}

\section{Electronic searches}

We developed detailed search strategies and completed them for the following electronic databases:

- Cochrane Central Register of Controlled Trials (CENTRAL) (2012, Issue 2)

- MEDLINE (January 1946 week 1 to February week 3 2012)

- EMBASE (January 1988 week 1 to February week 3 2012)

- CINAHL (January 1981 week 1 February 2012)

- PsycINFO (January 1987 week 1 to February week 22012)

The search used a combination of controlled vocabulary and free-text terms developed in consultation with an expert medical librarian and with Trial Search Co-ordinators for the Cochrane Gynaecological Cancer Review Group. The search strategy was developed for MEDLINE and revised appropriately for each database. The search terms employed for each bibliographic database can be found in Appendix 1.

\section{Language}

We placed no language restriction on the searches. We used translation services within Queen's University Belfast when necessary.

\section{Searching other resources}

We completed 'key word' searches on a range of Internet search engines, whilst we also searched the reference lists and bibliographies of all retrieved articles for further potentially relevant papers.

\section{Data collection and analysis}

\section{Selection of studies}

We downloaded the results of the searches into a reference manager database (RefWorks) and DS and MM removed duplicates. $D S, M M, A B, M C, A C, C C$ and $M D$ were involved in the subsequent selection of studies. Three pairs of review authors reviewed the remaining titles and abstracts and independently screened them for suitability, according to the following basic criteria:

- Randomised controlled trials (RCT), including quasi-RCTs, where the method of allocating people to intervention or control groups may not be truly random (e.g. based on date of birth or based on the order in which patients accessed treatment).

- Intervention comprised a physical and psychosocial component.

- Intervention was carried out on two or more occasions.

- Adult (aged 18 and over) cancer survivors.

- Patients were not currently receiving primary active treatment (e.g. surgery, chemotherapy or radiotherapy). 
- Outcomes included a physical outcome measure and a psychosocial outcome measure.

Studies which did not meet the inclusion criteria were excluded. When there was a lack of clarity, we obtained the full text of an article in order to determine whether or not it met the inclusion criteria. Following independent screening each pair of review authors (e.g. MC, MD) discussed their included and excluded studies. Any discrepancies were resolved by discussion between the pairs of review authors. A list of excluded trials and reasons for exclusion is included (Characteristics of excluded studies).

\section{Data extraction and management}

Pairs of review authors independently extracted data from the original studies using pre-designed data extraction forms and then counterchecked the data. Data extracted included the following information:

- General: author, year of publication, title, journal, country and language of publication

- Trial: study design, randomisation, allocation concealment, level of blinding

- Participant: diagnosis, cancer stage, age, gender, ethnicity, sample size and distribution of participants in each arm of the trial

- Intervention and control: components of intervention, method of delivery, setting, health professional involved, length of intervention, frequency, control intervention characteristics

- Methodological quality: see below

- Outcomes: physical, psychosocial, adherence, satisfaction and adverse events

\section{Assessment of risk of bias in included studies}

Pairs of review authors independently assessed the methodological quality of the selected studies and using a quality appraisal checklist coded them as follows:

- Random sequence generation (selection bias):

1. Low risk e.g. computer-generated random sequence or table of random numbers

2. High risk e.g. date of birth, day of week

3. Unclear e.g. insufficient information to permit judgement of 'low' or 'high'

- Allocation concealment (selection bias):

1. Low risk e.g. allocation concealment using telephone randomisation or sequentially numbered, opaque, sealed envelopes

2. High risk e.g. research or healthcare staff aware of arm to which participants were assigned

3. Unclear e.g. insufficient information to permit judgement of 'low' or 'high'

- Blinding (performance bias and detection bias):

Blinding of outcome assessors was coded as:

1. Low risk e.g. blinding ensured and unlikely to be broken

2. High risk e.g. no blinding of outcome assessment or could have been broken
3. Unclear e.g. insufficient information to permit judgement of 'low' or 'high'

- Incomplete outcome data (attrition bias):

1. Low risk e.g. no missing outcome data or attrition rate/loss to follow-up clearly accounted for

2. High risk e.g. imbalance in number of reasons for missing data across the groups or 'as-treated' analysis carried out

3. Unclear e.g. insufficient information to permit judgement of 'low' or 'high'

- Selective reporting (reporting bias):

1. Low risk e.g. all pre-specified outcomes were reported

2. High risk e.g. one or more outcome was reported incompletely

3. Unclear e.g. insufficient information to permit judgement of 'low' or 'high'

- Other bias

1. Low risk: study appeared free of other sources of bias

2. High risk: had sources of bias specific to the study design or some other problem or there were claims of fraudulence

3. Unclear e.g. insufficient information to permit judgement of 'low' or 'high'

We used the information collected in the 'Risk of bias' tool in RevMan 5.1 to assess the quality of each study.

\section{Sensitivity analysis}

We planned a meta-analysis of primary and secondary endpoints if sufficient good-quality trials with comparable populations, similar interventions and comparable outcomes were identified. However, due to heterogeneity among the studies in terms of the nature of the interventions and outcome measures, a quantitative analysis was not possible in most cases. Only the SF-36 provided sufficient data to conduct a quantitative analysis. We assessed heterogeneity using the $1^{2}$ statistic. Where marked heterogeneity was identified $\left(1^{2}\right.$ greater than $75 \%$ ) the results of the meta-analysis were included to validate the results of the narrative analysis. We grouped the remaining data according to the components of interventions and completed a narrative analysis. This analysis was structured and organised according to: the nature of an intervention; specific cancer sites or diagnoses versus generic site programmes; mode of delivery (e.g. face-to-face, print material or telephone); duration (short-term - less than six months versus long-term - more than six months); number of contacts; and type of health professional.

\section{RESULTS}

\section{Description of studies}

See: Characteristics of included studies and Characteristics of excluded studies.

\section{Results of the search}

The electronic searches identified 25,824 articles. Following removal of duplicates and an initial title screen, 24,571 articles were excluded. The initial screen excluded articles where it was clear from the title that the article related to:

- guidelines or a discussion paper NOT a research paper;

- reviews or meta-analyses;

- children NOT adults; 
- non-cancer patients;

- prevention or screening programmes;

- patients currently receiving treatment.

We examined the abstracts of the remaining 1253 papers and excluded a further 1125 papers for the following reasons:

- not a randomised controlled trial (RCT);

- patients currently receiving treatment;

- uni-dimensional interventions containing only a physical component or a psychosocial component;

- intervention delivered by peers or lay people.

We scrutinised full papers for 128 papers and eliminated 105 papers for the following reasons:

- non RCTs;

- interventions were being provided to patients who were also receiving primary active treatment;

- interventions targeted at the acute effects of treatment or a specific subgroup of patients e.g. obese patients;

- uni-dimensional interventions (focusing on either physical or psychosocial well-being);

- outcomes determined using non-validated tools;

- conference or dissertation abstracts;

- inappropriate control group.

We deemed 26 papers suitable for inclusion.

\section{Included studies}

Fourteen of the 26 articles that were included initially were supplementary papers providing information on: pilot work or design (Berglund 2003; Carmack 2004; Demark-Wahnefried 2003; Demark-Wahnefried 2003a); subgroup, additional outcomes or specific additional analyses (Carmack 2007; Ornish 2005; Korstjens 2008; May 2008b; May 2009; Mosher 2008; Snyder 2008; van Weert 2010) or long-term follow-up (Frattaroli 2008). Thus, a total of 12 studies were included in the review. The studies were conducted in six countries, seven in the USA (Carmack Taylor 2006; Daubenmier 2006; Demark-Wahnefried 2006; Demark-Wahnefried 2007; Giesler 2005; Lepore 1999; Rogers 2009), one in Sweden (Berglund 2007), Canada (Fillion 2008), China (Bai 2004), New Zealand (Bennett 2007) and the Netherlands (May 2008a). With the exception of Bai 2004, which was written in Chinese, the remaining 11 studies were written in English.

\section{Participants}

The studies recruited between 24 (Lepore 1999) and 543 (Demark-Wahnefried 2007) participants. In total 1669 patients were recruited. Prostate (876) and breast (683) cancer patients respectively were the most commonly recruited, with five prostate cancer-specific studies (Berglund 2007; Carmack Taylor 2006; Daubenmier 2006 ; Giesler 2005; Lepore 1999), two breast cancer-specific studies (Fillion 2008; Rogers 2009) and one nasopharyngeal-specific study (Bai 2004). The remaining four studies recruited participants with a range of cancer diagnoses.

\section{Interventions and controls}

In all 12 studies, participants were randomised to the intervention group or control group(s). Control groups differed across studies. For example, in seven studies the control group comprised standard care only (Bai 2004; Berglund 2007; Daubenmier 2006; Fillion 2008; Giesler 2005; Lepore 1999; Rogers 2009). Five studies used a control group where participants received a lesser form of the intervention (Bennett 2007; Carmack Taylor 2006; DemarkWahnefried 2006; Demark-Wahnefried 2007; May 2008a).

The protocol for this review stated that an intervention must contain a physical component (e.g. exercise, dietary regime) and a psychosocial component (e.g. counselling, cognitive behavioural therapy, psycho-educational strategies). While all 12 studies met this criteria they fell into two distinct categories:

- Seven studies stated explicitly that the aim of the rehabilitation programme was to promote physical and psychosocial well-being; they incorporated physical and psychosocial components and measured physical and psychosocial outcomes (Bai 2004; Carmack Taylor 2006; Daubenmier 2006; Fillion 2008; Giesler 2005; May 2008a; Rogers 2009).

- Five studies focused on improving only one aspect of well-being (predominantly physical functioning), although physical and psychosocial components and related outcomes were included in the programme (Bennett 2007; Berglund 2007; DemarkWahnefried 2006; Demark-Wahnefried 2007; Lepore 1999).

In most studies $(\mathrm{n}=10)$ the intervention was delivered via face-to-face contact with a professional. Four studies also included additional follow-up telephone contacts (Bennett 2007; Daubenmier 2006; Fillion 2008; Giesler 2005). The remaining two studies, both by Demark-Wahnefried, used printed material to deliver their intervention. One study (Project LEAD, DemarkWahnefried 2006) supplemented the mailed material with telephone counselling; however, the other study (FRESH START, Demark-Wahnefried 2007) developed a distance 'medicine-based' intervention which allowed a large number of patients (543) to be recruited from across 39 states and two provinces in North America and lasted 10 months. Only one other study, which utilised a oneweek residential stay followed by telephone calls, was maintained for 12 months (Daubenmier 2006). The study which had the shortest duration (Fillion 2008) lasted for four weeks, stating that this time period was more manageable for participants who were weakened by their treatment and condition. In addition, a shorter intervention was seen as being more cost-effective and attractive to Cancer Centres. Interventions also varied in the number of contacts provided, from four (Bennett 2007) to 24 (Carmack Taylor 2006).

Interventions were delivered by a variety of professionals. Most studies utilised two or more professionals. Only two studies involved just one health professional; Bennett utilised a physical activity counsellor (Bennett 2007), while Giesler's study featured a nurse-led intervention (Giesler 2005). Professionals from a physical therapy background were most commonly involved and took an active role in seven of the studies (Bennett 2007; Berglund 2007; Carmack Taylor 2006; Demark-Wahnefried 2006; Fillion 2008; May 2008a; Rogers 2009) although nurses were also frequently involved (Berglund 2007; Daubenmier 2006; Fillion 2008; Giesler 2005; Lepore 1999). One study used a clinical psychologist to deliver the psychosocial intervention to groups of participants (Rogers 2009). Two studies did not provide information on the type of professionals involved (Bai 2004; Demark-Wahnefried 2007). 
Physical intervention components included either exercise or dietary interventions and could be categorised into two main groups:

- Supervised physical training (Berglund 2007; Fillion 2008; May 2008a; Rogers 2009)

- Prescribed, advised, encouraged or directed to change diet or increase activity levels (Bai 2004; Bennett 2007; Carmack Taylor 2006; Daubenmier 2006 ; Demark-Wahnefried 2006; DemarkWahnefried 2007; Giesler 2005; Lepore 1999)

The most intensive of these programmes was implemented by Daubenmier 2006 who prescribed a very low-fat vegan diet, moderate aerobic exercise (walking 30 minutes six days per week), stress management techniques (60 minutes daily) and a one-hour support group once weekly for one year.

Similarly the psychosocial components varied considerably. However, they could be broadly categorised into those which:

- provided information (Berglund 2007; Giesler 2005) and support (Daubenmier 2006);

- utilised psychological processes to change behaviour e.g. motivational interviewing (Bennett 2007), social cognitive theory (Demark-Wahnefried 2006; Demark-Wahnefried 2007; Rogers 2009); CBT (Bai 2004; Carmack Taylor 2006; Fillion 2008; Lepore 1999; May 2008a).

\section{Outcomes}

The 12 studies employed a variety of outcome measures, and assessed participants at different time points and over varying follow-up periods. The most commonly used outcome measure was the SF-36 (Ware 1993), used in seven studies (Bennett 2007; Carmack Taylor 2006; Daubenmier 2006; Demark-Wahnefried 2006; Fillion 2008; Giesler 2005; Lepore 1999). The SF-36 includes eight sub-scales that independently measure aspects of physical and psychosocial health. In addition, two summary scores can be calculated. Although seven studies utilised the SF-36 the actual values that were reported varied in terms of specific subscales and summary scores and in terms of the statistical indices (group mean and mean change scores) thereby limiting the number of studies that could be included in the meta-analysis (Analysis 1.1). Despite these variations a consistent effect was identified in the SF-36 physical health component scale. An increase in SF-36 physical function of $2.22(95 \% \mathrm{Cl} 0.12$ to $4.31, \mathrm{P}=0.04)$ was identified in the intervention group compared with the control group for five studies (Figure 1). It should be noted that the assessment time point varied from three to 12 months for these studies; this was largely dependent upon the duration of the programme under investigation. There was no evidence of heterogeneity between studies in this effect $(12=0 \%)$. The SF-36 mental health component score was available for four studies (Analysis 2.1; Figure 2), however, in this instance considerable heterogeneity was identified $\left(1^{2}=\right.$ $84 \%)$.

Figure 1. Forest plot of comparison: 1 Physical, outcome: 1.1 SF-36 Physical Component Score.

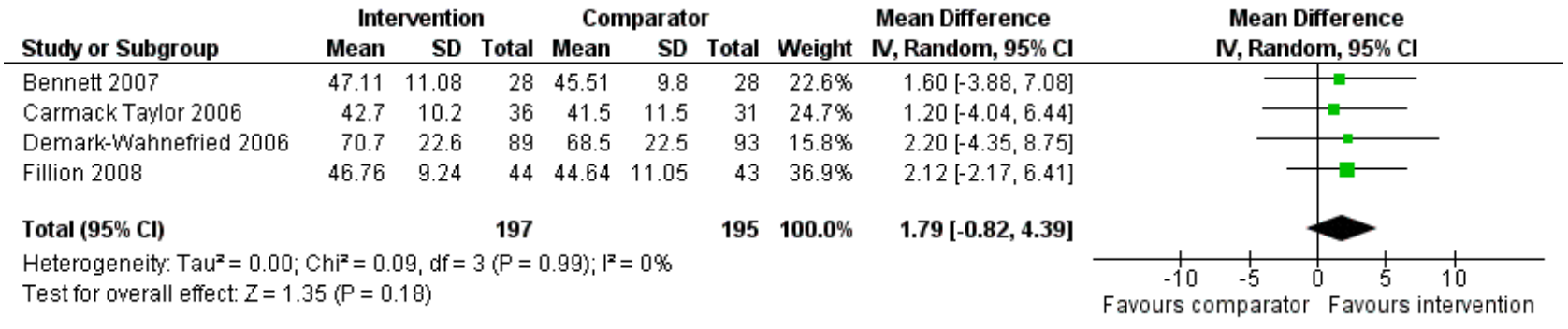

Figure 2. Forest plot of comparison: 2 Psychosocial, outcome: 2.1 SF-36 Mental Component Summary.

\begin{tabular}{|c|c|c|c|c|c|c|c|c|c|}
\hline \multirow[b]{2}{*}{ Study or Subgroup } & \multicolumn{3}{|c|}{ Intervention } & \multicolumn{3}{|c|}{ Comparator } & \multirow{2}{*}{$\begin{array}{l}\text { Mean Difference } \\
\text { IV, Random, } 95 \% \mathrm{CI}\end{array}$} & \multirow{2}{*}{\multicolumn{2}{|c|}{$\begin{array}{c}\text { Mean Difference } \\
\text { IV, Random, } 95 \% \mathrm{Cl}\end{array}$}} \\
\hline & Mean & SD & Total & Mean & SD & Total & & & \\
\hline Bennett 2007 & 44.42 & 8.24 & 20 & 51.68 & 5.98 & 26 & $-7.26[-11.54,-2.98]$ & $\longrightarrow$ & \\
\hline Carmack Taylor 2006 & 53.7 & 6.8 & 36 & 53.4 & 10.4 & 31 & $0.30[-3.98,4.58]$ & & \\
\hline Fillion 2008 & 51.38 & 7.57 & 44 & 47.96 & 9.3 & 43 & $3.42[-0.15,6.99]$ & & - \\
\hline Total $(95 \% \mathrm{Cl})$ & & & 100 & & & 100 & $-1.11[-7.34,5.13]$ & & \\
\hline $\begin{array}{l}\text { Heterogeneity: } \operatorname{Tau}^{2}= \\
\text { Test for overall effect: }\end{array}$ & $\begin{array}{l}5.11 ; \mathrm{Ch} \\
=0.35(\mathrm{~F}\end{array}$ & $\begin{array}{l}i^{2}=14 \\
=0.7\end{array}$ & 34, $d f=$ & $=2(\mathrm{P}=$ & 0.000 & 8); $\left.\right|^{2}=8$ & $86 \%$ & $\begin{array}{cc}10 & -5 \\
\text { Favours intervent }\end{array}$ & $\begin{array}{c}5 \\
\text { Favours c }\end{array}$ \\
\hline
\end{tabular}

Secondary outcomes for this review included adherence, satisfaction and adverse outcomes. These outcomes were not widely reported. The five studies which discussed adherence (Bennett 2007; Carmack Taylor 2006; Demark-Wahnefried 2007; May 2008a; Rogers 2009) reported levels of adherence of over $64 \%$. There was variation across studies that reported adverse events. Carmack Taylor 2006 and Rogers 2009 reported no adverse events, May 2008a reported one death which was not attributable to the intervention, Demark-Wahnefried 2006 stated that there were no differences between arms with regard to the number or level of adverse events and Demark-Wahnefried 2007 reported the number of serious adverse events for each arm (35 out of 271 , 39 out of 272) but did not clarify their nature. Satisfaction was measured 
by only three studies (Carmack Taylor 2006; Demark-Wahnefried 2007; Rogers 2009), all of which reported positive findings.

\section{Excluded studies}

The reasons for the exclusion of 12 studies are included in Characteristics of excluded studies. The primary reasons for exclusion were that a high percentage of participants were receiving active treatment (five studies) (Courneya 2003; Cunningham 1989; Fan 2006; Johansson 2008; Zhang Tong 2005) and four studies had not used validated outcome measures (Berglund 1994; Bloom 2008; Cain 1986; Cho 2006). The remaining three studies were excluded because they were not multidimensional (Heim 2007); one trial tested two different time plans of delivery instead of two different programmes (Hartmann 2007); and, in one trial (van Weert 2005), the majority of people in the control group also received the full MDRP programme.

\section{Risk of bias in included studies}

We assessed all studies for risk of bias using the RevMan 5.1 'Risk of bias' tool (RevMan 2011). This tool assesses studies according to the following criteria: random sequence generation, allocation concealment, blinding, incomplete outcome data, selective reporting and other sources of bias (Figure 3; Figure 4). This allows the overall risk of bias for each study to be calculated according to the following categories: 
Figure 3. 'Risk of bias' summary: review authors' judgements about each risk of bias item for each included study.

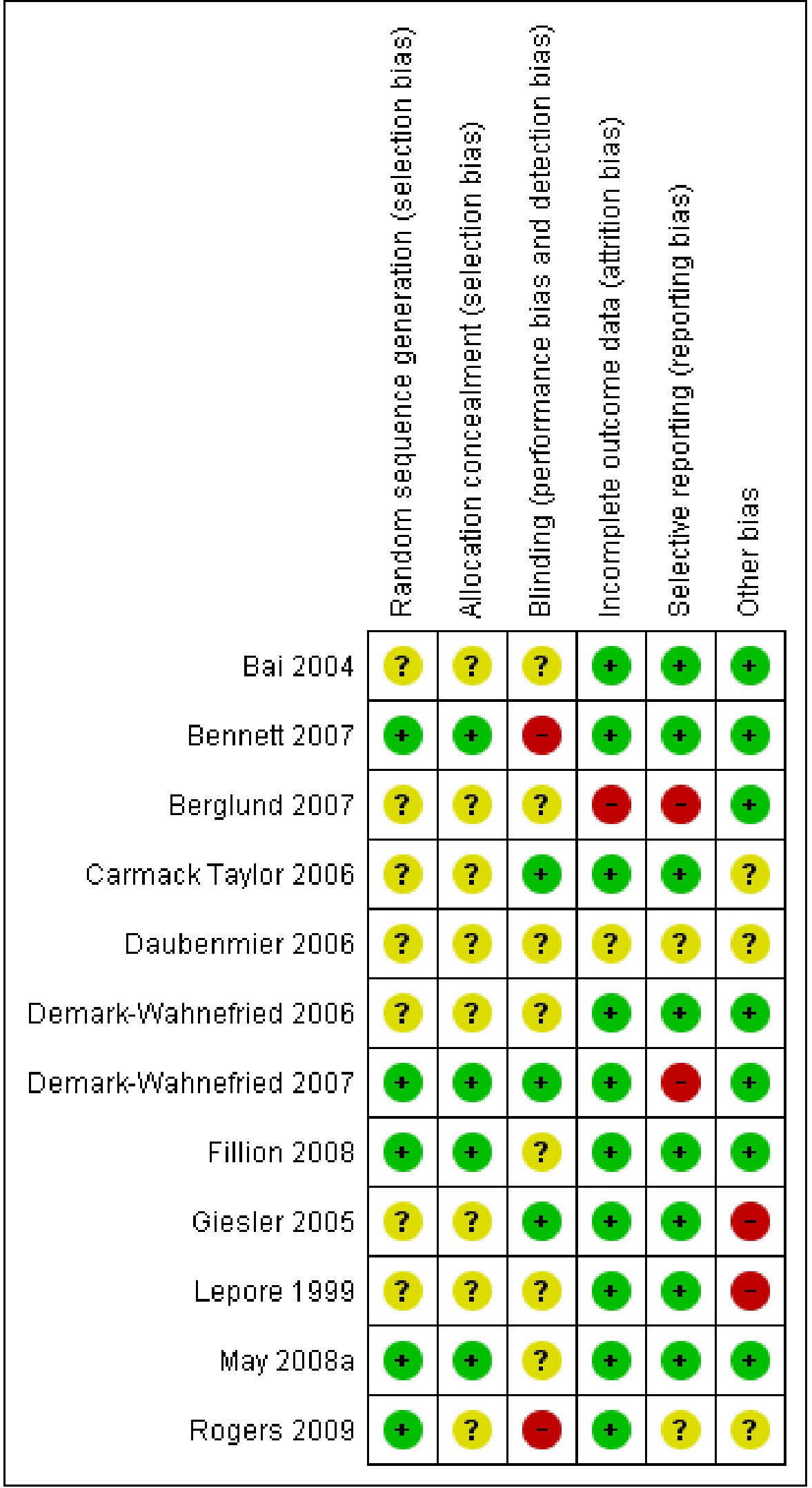


Figure 4. 'Risk of bias' graph: review authors' judgements about each risk of bias item presented as percentages across all included studies.

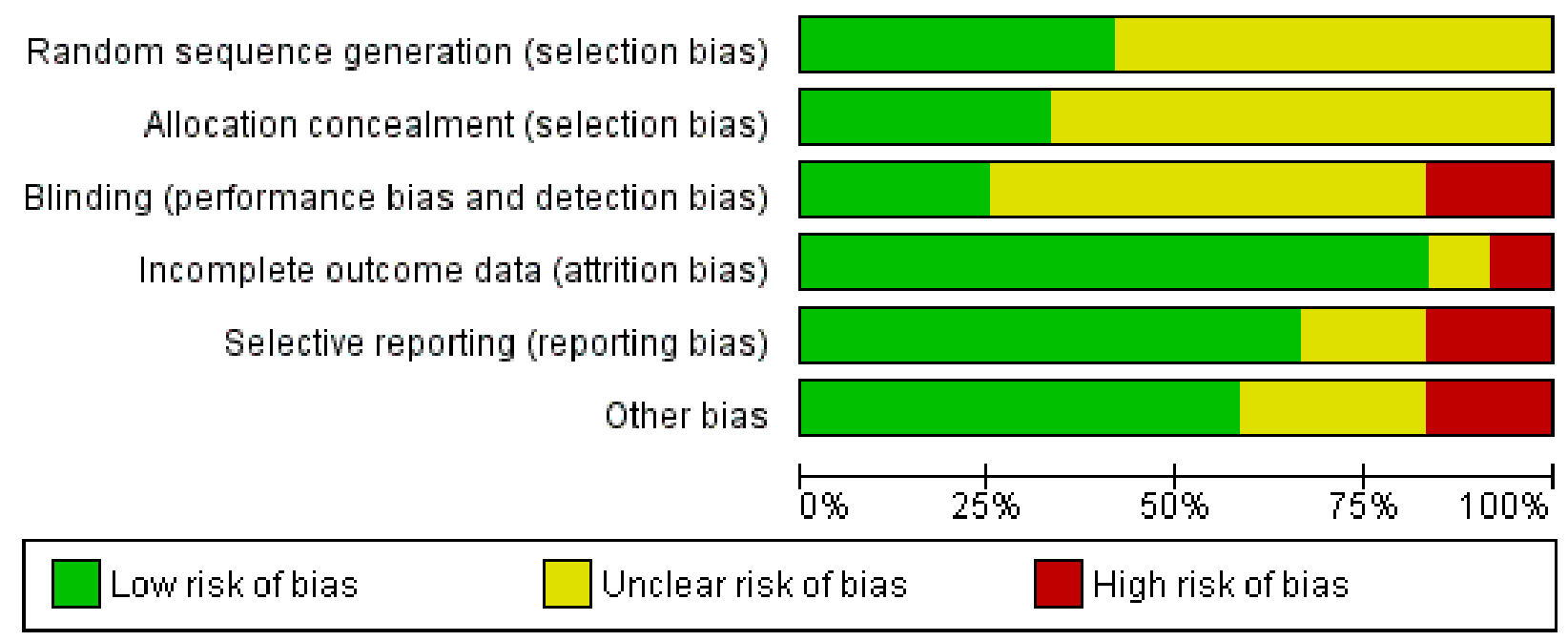

- Low: all criteria met

- Moderate: one or two criteria unclear or not met

- High: more than two criteria unclear or not met

No studies had a low risk of bias. Four of the 12 studies had a moderate risk of bias (Bennett 2007; Demark-Wahnefried 2007; Fillion 2008; May 2008a) and we classified eight as having a high risk of bias (Bai 2004; Berglund 2007; Carmack Taylor 2006; Daubenmier 2006; Demark-Wahnefried 2006; Giesler 2005; Lepore 1999; Rogers 2009). The criteria for risk of bias is described in detail below.

\section{Random sequence generation}

The inclusion criteria required all studies to be randomised. However, only five studies (Bennett 2007; DemarkWahnefried 2007; Fillion 2008; May 2008a; Rogers 2009) clearly stated a method of random sequence generation using either a computer-generated or a random number list. We classified these studies as being of low risk of bias. The other studies did not clarify the method that they used and so we classified them as 'unclear'

\section{Allocation}

Likewise, five studies (Bennett 2007; Demark-Wahnefried 2007; Fillion 2008; May 2008a; Rogers 2009) clearly stated a method of allocation concealment that was considered to be of low risk. These methods included allocation from a central location or by sequentially numbered, opaque, sealed envelopes. The remaining studies did not describe in sufficient detail the method of concealment and we classified them as 'unclear'.

\section{Blinding}

Due to the nature of the interventions being delivered it was not possible to blind the participants or researchers to the allocated interventions. Instead, we assessed studies in relation to the blinding of outcome assessment. Four studies (Carmack Taylor 2006; Daubenmier 2006; Demark-Wahnefried 2007; Giesler 2005) clearly stated that the assessors were blinded to outcomes. Six studies did not provide sufficient detail and we classified them as unclear. We classified the remaining studies (Bennett 2007; Rogers
2009) as being of high risk of bias as the physical activity specialists who delivered the interventions were involved in assessing the outcomes (this was noted as a limitation in the studies).

\section{Incomplete outcome data}

A high level of missing data or poor handling of missing data leads to attrition bias. Fortunately, most studies $(n=11)$ clearly stated and explained their loss to follow-up and demonstrated that attrition was balanced between the groups. We considered only one study (Berglund 2007) to be at high risk of attrition bias due to participants in two of four groups (physical training only and the control group) failing to return questionnaires.

\section{Selective reporting}

There was no evidence of selective reporting in 10 of the studies. Two studies did demonstrate some degree of reporting bias and did not report all of the pre-specified outcomes. Berglund 2007 did not provide EORTC data at 12 months for each group though they did state that health-related quality of life (HRQOL) did not change by intervention or time. Instead they provided HRQOL data for patients with and without metastases. Likewise Demark-Wahnefried 2007 did not report the results from the risk of depression and social support questions that were included in their questionnaires.

\section{Other potential sources of bias}

We assessed three studies (Daubenmier 2006; Giesler 2005; Lepore 1999) as having an additional risk of bias. This related primarily to the fact that the authors did not state clearly that they had implemented an intention-to-treat analysis (ITT). In addition, one study Lepore 1999 had a very limited follow-up period of two weeks.

\section{Effects of interventions}

Two studies did not find a beneficial effect for the multidimensional rehabilitation programme (MDRP) intervention in terms of a physical or a psychosocial outcome (Berglund 2007; Carmack 
Taylor 2006). Seven studies showed a beneficial effect in one of the two outcome categories (Bennett 2007; Daubenmier 2006; DemarkWahnefried 2006; Demark-Wahnefried 2007; Giesler 2005; Lepore 1999; May 2008a). The remaining three studies showed significant effects in terms of both physical and psychosocial outcomes (Bai 2004; Fillion 2008; Rogers 2009).

\section{Multi- or uni-dimensional focus}

As outlined earlier the interventions fell into two broad categories interventions which explicitly aimed to improve functioning in both outcome domains (physical and psychosocial) and interventions which focused on one domain only. The first category referred to as interventions with a multidimensional focus (MDF) and the second category is referred to as interventions with a uni-dimensional focus (UDF).

The seven MDF studies (Bai 2004; Carmack Taylor 2006; Daubenmier 2006; Fillion 2008; Giesler 2005; May 2008a; Rogers 2009) recruited 653 participants in total. However, the findings were inconsistent. Four studies used cognitive behaviour therapy (CBT) combined with physical exercise (Bai 2004; Carmack Taylor 2006; Fillion 2008; May 2008a). As highlighted above, Carmack Taylor 2006 found no statistically significant improvement in either physical or psychosocial outcomes. This study, entitled 'Active for Life' (Carmack Taylor 2006), evaluated the efficacy of a six-month group-based lifestyle physical activity programme to improve the quality of life $(\mathrm{QoL})$ of prostate cancer patients compared to an educational programme and standard care. The lifestyle programme participants were taught CBT skills to help them undertake and maintain regular physical activity (30 minutes of moderate activity prescribed for most days of the week). The control group was provided with the same educational component, but did not receive CBT. The authors cite high baseline scores and an insufficient sample size as possible reasons for no statistically significant improvement among intervention participants compared to the control group. They concluded that a lifestyle programme which focused on cognitive-skills training and education was insufficient to improve the QoL of prostate cancer patients.

May 2008a also utilised CBT, but combined it with a supervised physical training (PT) programme (PT plus CBT) and compared it to an attention control arm which received the physical training programme alone and a waiting list control group. The study was reported in four papers; one paper detailed the physical outcomes, one presented QoL outcomes, one paper combined both outcomes and the fourth paper examined cancer-related fatigue (May 2008a). While this study showed a significant improvement in physical fitness (as measured by the 12-item Physical Activity Scale for the Elderly (PASE)) from baseline in both intervention groups (PT mean difference 2.1 (95\% $\mathrm{Cl} 1.2$ to 3.0); PT plus CBT mean difference 2.0 $(95 \% \mathrm{Cl} 1.1$ to 2.9$)$; $\mathrm{P}<0.0001)$ there was no statistically significant difference between the groups (mean difference $-0.1,95 \% \mathrm{Cl}-1.5$ to $-1.3, \mathrm{P}$ not provided). No psychosocial improvements were detected between the intervention groups during the three-month follow-up period. However, when compared to a waiting list control group, statistically and clinically relevant improvements were noted for both rehabilitation intervention arms in terms of physical role limitations (change 20.8 (8.9 to 32.7 ) $\mathrm{P}<0.001$ ), physical functioning (change 9.4 (5.1 to 13.6$) P<0.001$ ), vitality (change 9.8 (5.3 to 14.3 ) $P<0.001$ ) and health change (change 25.7 (16.8 to 34.5) $P<0.001$ ). The authors concluded that adding a structured CBT intervention to a group-based self management physical training programme did not enhance the overall effect.

Similarly, Bai 2004 examined the effect of combined CBT and exercise therapy on the QoL of nasopharyngeal cancer patients compared to a standard care group. This study showed statistically significant improvements in five areas of functioning compared to the control group: physical (mean difference $-4.61, \mathrm{P}<0.01$ ), cognitive (mean difference 2.38, $P<0.05$ ), emotional (mean difference -3.69, $P<0.01$ ), fatigue (mean difference $-5.84, P<0.01$ ) and general QoL (mean difference -4.26, $\mathrm{P}<0.01$ ). However, it is important to note that this was a small study $(n=45)$ and it was classified as having a high risk of bias because details of random sequence generation, group allocation or blinding of the outcomes were not provided. In addition, information about a sample size calculation was not included and it was not clear whether or not they met their target recruitment number to identify statistically significant findings.

Fillion 2008 also developed a group intervention that combined stress management using cognitive and behavioural strategies with physical activity to reduce fatigue and improve energy levels, QoL, fitness and emotional distress. This short four-week intervention for breast cancer survivors showed that participants in the intervention group had greater improvement in fatigue score (intervention mean $(M)=2.40$ (standard deviation (SD) 0.84), control $M=2.75$ (SD 0.93); $P=0.03$ ), energy levels (intervention $M$ $=2.63(\mathrm{SD} 0.72)$, control $\mathrm{M}=2.24(\mathrm{SD} 0.88) ; \mathrm{P}=0.01$ ) and emotional distress (intervention $M=11.15$ (SD 3.85), control $M=13.13$ (SD 5.44); $P=0.04$ ) compared to the standard care control group. We assessed this study as having a moderate risk of bias because the authors did not state whether or not the outcomes assessment had been blinded.

The intervention in the Rogers 2009 study was based on a social cognitive model and comprised group discussions facilitated by a Clinical Psychologist, supervised exercise, home-based exercise and face-to-face counselling sessions with an exercise specialist. This 12-week intervention for breast cancer survivors receiving hormone therapy found improvements in objective measures of physical fitness and psychosocial measures including physical activity as measured by accelerometer (mean difference (MD) $72.103 ; 95 \% \mathrm{Cl} 25,383$ to 119,000 ; effect size $(d)=1.02 ; \mathrm{P}=0.004)$, back/leg muscle strength (MD 12.3; 95\% $\mathrm{Cl} 0.4$ to $15.9 ;(d)=0.81 ; \mathrm{P}=$ 0.017 ), waist-to-hip ratio (MD $-0.05 ; 95 \% \mathrm{Cl}-0.01$ to $-0.08 ;(d)=-0.77$; $\mathrm{P}=0.018$ ) and social well-being as measured by the Functional Assessment of Cancer Therapy - Breast (FACT-B) measure (MD 2.0; $95 \% \mathrm{Cl} 0.3$ to $3.8 ;(d) 0.76 ; \mathrm{P}=0.03$ ) compared to a standard care control group who received information only. However, it should be noted that the study was based on a small sample $(n=41)$, and it was not possible to analyse potential moderating factors such as demographic variables, age or readiness to change. In addition, we assessed the study as having a high risk of bias because exercise specialists who completed the objective physical measures were not blinded to participant group allocation.

The remaining two MDF studies (Daubenmier 2006; Giesler 2005) did not use a specific psychotherapeutic approach such as CBT. Instead, they provided general psycho-education (Giesler 2005) or psycho-education specific to stress management (Daubenmier 2006). 
Daubenmier 2006 developed the most intensive intervention for men undergoing active surveillance for prostate cancer. Experimental group patients were prescribed an intensive lifestyle programme that included a vegan diet supplemented with soy (one daily serving of tofu plus $58 \mathrm{~g}$ of a fortified soy protein powdered beverage), fish oil ( 3 g daily), vitamin E (400 IU daily), selenium ( $200 \mu \mathrm{g}$ daily) and vitamin C (2 g daily), moderate aerobic exercise (walking 30 minutes six days weekly), stress management techniques (gentle yoga-based stretching, breathing, meditation, imagery and progressive relaxation for a total of 60 minutes daily) and participation in a weekly one-hour support group to enhance adherence to the intervention. The intervention was maintained for one year and outcomes were compared with a standard care control group. This study was reported in two papers. No statistically significant group differences were observed for physical or psychosocial QoL scores. However, the authors highlighted that the baseline scores for participants were high and that this ceiling effect left little room for improvement, though individuals who improved their lifestyle enhanced their QoL. The intervention did affect cancer progression: men in the intervention group had a significant reduction in their PSA (prostate-specific antigen) values (intervention $-4 \%$, control $+6 \%, P=0.01$ ) and in the growth of LNCaP prostate cancer cells, which is a measure of prostate cancer progression (intervention $70 \%$, control $9 \%, \mathrm{P}<$ 0.001).

The final MDF study (Giesler 2005) developed a unique nurse-led, computer-assisted intervention that randomised patient-spouse dyads to the intervention or a standard care arm. Dyads in the intervention arm met once per month for six months with a nurse. The nurse identified and tracked QoL problems using a computer-based assessment programme. An extensive range of physical and psychoeducational strategies were available for each problem identified. The intervention had statistically significant long-term (up to 12 months) beneficial effects on sexual outcomes (intervention mean (M) 12.35 (SD 17.28), control $M=3.11$ (SD 19.61); $P=0.02$ ) and on cancer worry (intervention $M=14.15$ (SD 25.12), control $\mathrm{M}=3.07$ (SD 17.68); $\mathrm{P}=0.03$ ) compared to patient dyads receiving standard care. Some participants in the intervention group had high levels of baseline depression and they fared worse, relative to the control group. However, we classified the results from this study as having a high risk of bias because the authors did not specify their method of randomisation, allocation concealment or undertake intention-to-treat (ITT) analysis. In addition, the study had insufficient statistical power due to subject recruitment difficulties.

In summary, there is limited evidence to support the use of MDF programmes for cancer survivors. Only three studies (Bai 2004; Fillion 2008; Rogers 2009) showed both physical and psychosocial benefits for their programmes. However, as discussed, the studies had a moderate risk of bias (Fillion 2008) or a high risk of bias (Bai 2004; Rogers 2009). May 2008a also found positive outcomes for their rehabilitation programme, though the positive outcomes were attributed to the physical component per se and were not enhanced by including a psychosocial component.

The majority of UDF rehabilitation programmes (four out of five) found a significant effect for the stated aim or focus of the given programme. Berglund 2007 did not find improvement in the intervention or control group. Studies that had a stated aim of improving physical functioning showed significant improvements in at least one physical outcome. The interventions did not have any significant effect on psychosocial outcomes, though this was not a goal of the programmes.

Bennett 2007 used motivational interviewing (MI) to increase physical activity and improve aerobic fitness, health and fatigue in a small $(n=56)$ mixed group of participants. The intervention arm self reported a significantly higher level of physical activity with a mean increase in energy expenditure of $1556 \mathrm{kcal} / \mathrm{wk}$ compared to an increase of $397 \mathrm{kcal} / \mathrm{wk}$ in the control group $(P<0.05)$. However, it should be noted that the mean level of regular activity at baseline was significantly lower $(P=0.04)$ in the intervention group than in the control group. Motivational interviewing did not have a statistically significant effect on mental health status.

Demark-Wahnefried 2006 developed a home-based diet and exercise programme known as Project LEAD, to improve lifestyle behaviours and ultimately enhance physical functioning. Project LEAD showed a statistically significant improvement in diet quality over the six-month period (intervention +2.2 , control -2.9 ; $\mathrm{P}=$ $0.003)$. Change in physical function did not reach significance ( $P$ $=0.23$ ). The improvements in the intervention arm did diminish during the post-intervention period. Although the study was relatively large $(n=182)$ it did not achieve the expected or required recruitment rate. In addition, the authors did not provide clear information about random sequence generation, allocation concealment or blinding of outcome assessors and the study was classified as having a high risk of bias.

Similarly, the Demark-Wahnefried 2007 second study, entitled the FRESH START trial, aimed to improve diet and exercise practices of breast and prostate cancer survivors through a tailored printed intervention delivered via mail. This study achieved a high recruitment rate $(n=543)$ and observed a significant mean difference between arms in the practice of two or more lifestyle behaviours (intervention $+34 \%$, control $+18 \%$; $\mathrm{P}<0.001$ ). While the attention control arm showed improvement in outcomes, the intervention arm showed significantly greater improvements in mean scores for exercise minutes per week (intervention +59.3 , control +39.2; $P=0.02$ ), fruit and vegetable consumption (intervention +1.1 servings, control $+0.6 ; P=0.01$ ), decreased fat intake (intervention $-4.4 \%$, control $-2.1 \% ; \mathrm{P}<0.001$ ) and reduced body mass index (BMI) (intervention -0.3 , control $+0.1 \mathrm{~kg} / \mathrm{m}^{2} ; \mathrm{P}$ $=0.004)$. Significant changes in psychosocial outcomes such as depression, social support and quality of life were not noted for either arm over the duration of the study, though there may have been a ceiling effect at baseline measurement.

Only one UDF study, Lepore 1999, explicitly stated the aim of promoting psychosocial aspects of care though they incorporated and assessed physical aspects. Lepore 1999 included an educational session on 'Cancer, diet and exercise' and assessed physical and mental health outcomes using the SF-36; interpersonal conflict using the Lepore Social Conflict Scale; and a variety of measures of cognitive processing. This small study $(n=24)$ showed that intervention participants had greater improvements in mean mental health scores over time (intervention +14.33 , control $+0.67 ; P<0.05$ ), fewer interpersonal conflicts with their wife (intervention +0.3 , control $-0.05 ; P<0.01$ ), improved self efficacy (intervention +0.19 , control $+0.06 ; P<0.05$ ) and lower levels of distress associated with cancer-related thoughts (intervention -0.46 , control +0.17 ; $\mathrm{P}<0.05$ ). Mean physical functioning scores 
were not significantly affected by the intervention. Similar to other studies, we classified Lepore 1999 as having a high risk of bias because it did not provide information about the method of random sequence generation, allocation concealment or blinding of outcome assessors.

Overall, current rehabilitation programmes with a uni-dimensional or focused aim rather than a multidimensional aim or focus appear to be more successful in terms of effecting positive change in the domain directly related to their focus.

\section{Cancer site-specific and mixed site programmes}

Eight studies examined programmes delivered to participants with site-specific cancer diagnoses. Five studies featured prostate cancer patients (Berglund 2007; Carmack Taylor 2006; Daubenmier 2006; Giesler 2005; Lepore 1999), and two studies comprised breast cancer patients (Fillion 2008; Rogers 2009) and one nasopharyngeal patients (Bai 2004). These programmes had a mixed effect on physical and psychosocial outcomes. Two studies identified no effect on either outcome (Berglund 2007; Carmack Taylor 2006), four studies identified a positive significant effect on both outcomes (Bai 2004; Fillion 2008; Giesler 2005; Rogers 2009) and the remaining two (Daubenmier 2006; Lepore 1999) identified a positive significant effect in one of the two main outcome categories under review. In contrast, the four studies which delivered their intervention to a group of mixed diagnoses cancer patients (Bennett 2007; Demark-Wahnefried 2006; DemarkWahnefried 2007; May 2008a) reported at least one significant group difference in favour of the intervention in relation to physical outcomes. However, none of the mixed site studies identified a significant effect in relation to psychosocial outcomes.

\section{Mode of delivery}

In six studies the MDRP was delivered via face-to-face contact between participants and professionals (Bai 2004; Berglund 2007; Carmack Taylor 2006; Lepore 1999; May 2008a; Rogers 2009). Only two of the six studies (Bai 2004; Rogers 2009) showed positive significant physical and psychosocial effects. Two out of the five studies (Lepore 1999; May 2008a) reported a positive significant physical or psychosocial outcome. The remaining two studies showed no improvement in any outcome measure. In contrast, face-to-face interventions supplemented with at least one booster telephone call showed a positive significant difference regarding physical outcomes in all four studies which used this mode of delivery (Bennett 2007; Daubenmier 2006; Fillion 2008; Giesler 2005). Psychosocial outcomes showed a significant difference in two of the four studies when a phone call was added to the intervention (Fillion 2008; Giesler 2005). Only two studies used print materials to deliver their intervention (Demark-Wahnefried 2006; Demark-Wahnefried 2007). Both studies reported improvements in physical outcomes (but not psychosocial outcomes) for members of the intervention group.

\section{Duration of intervention and number of contacts}

In relation to duration, studies fell into two groups - interventions delivered for less than six months (range four to 12 weeks) and interventions delivered for six months or more (range six to 12 months). Interventions that were delivered over a longer duration (Bennett 2007; Carmack Taylor 2006; Daubenmier 2006; DemarkWahnefried 2006; Demark-Wahnefried 2007) showed no additional improvement to interventions conducted over a period of up to
12 weeks (Bai 2004; Berglund 2007; Fillion 2008; Lepore 1999; May 2008a; Rogers 2009).

The number of contacts with participants during the interventions appeared to be unrelated to the duration of the programmes delivered, e.g. Bennett's intervention was delivered over six months and comprised four contacts between the professional and participants, whereas Roger's intervention comprised 21 face-toface contacts in 12 weeks and Berglund's intervention comprised seven contacts in seven weeks. Number of MDRP contacts did not appear to be associated with improvements in outcome. Indeed, only one of the studies (Rogers 2009) which involved seven or more contacts with participants (Berglund 2007; Carmack Taylor 2006; Daubenmier 2006; Demark-Wahnefried 2006; DemarkWahnefried 2007; May 2008a) found a significant psychosocial difference (as measured by the social well-being scale of the FACT$B$ questionnaire). In contrast, four of five studies which involved fewer than six contacts (Bai 2004; Fillion 2008; Giesler 2005; Lepore 1999) found a significant psychosocial effect in support of the intervention group.

\section{Professionals involved}

The majority of studies (10 out of 12) utilised two or more professionals to deliver the interventions, with mixed effect. In two papers the intervention was delivered by a single professional, again with mixed effects. The intervention reported in Bennett 2007 was delivered by a physical activity counsellor. A positive effect was found for physical activity only. Giesler 2005 used a nurseled intervention and found a positive effect for both physical and psychosocial outcomes.

\section{DISCUSSION}

\section{Summary of main results}

In this systematic review the evidence to assess the effectiveness of multidimensional rehabilitation programmes (MDRPs) was derived from 12 eligible studies. The studies involved participants with a range of cancer diagnoses who received a wide variety of interventions that were delivered using various methods, over different time periods and were assessed using numerous outcome measures. It was not meaningful to conduct a full statistical synthesis or meta-analysis due to this heterogeneity (Pettigrew 2006). However, we were able to pool data on the SF-36 in five of the studies. The pooled data detected a significant effect in the SF-36 physical health component scale Analysis 1.1. Participants who received a multidimensional rehabilitation intervention showed a consistent improvement in their physical functioning following the intervention compared to control participants. However, this finding was not replicated in the narrative synthesis of SF-36 mental health component scores Analysis 2.1. An individuals' ability to assess changes in their physical ability may be easier to measure than the ability to self assess psychological changes over time. Furthermore, it has been noted that there is a lack of clarity regarding psychological interventions and their assessment (Hodges 2011). The limited available studies appear to indicate that MDRPs exert a greater impact on physical functioning than on psychological well-being.

As discussed previously, due to high levels of heterogeneity, subgroup analysis was not possible. Thus, narrative analysis was undertaken to identify the possible effects of rehabilitation 
programmes according to: cancer site, mode of delivery, duration, frequency of contacts and the professionals involved. The findings of this analysis indicate, tentatively, that:

- rehabilitation programmes with a uni-dimensional focus may be more successful in terms of generating a positive change in the aspect directly related to their focus or primary aim;

- rehabilitation programmes that involve participants with a variety of cancer diagnoses show at least similar positive improvements in physical to cancer site-specific programmes;

- the most effective mode of delivery is face-to-face contact with a professional, supplemented with at least one follow-up telephone call;

- the positive effects of rehabilitation programmes appear to plateau after approximately six months;

- the type of healthcare professional does not appear to influence the delivery or outcome of rehabilitation programmes.

\section{Overall completeness and applicability of evidence}

Due to the diverse nature of the studies, there is insufficient evidence to assess the effectiveness of multidimensional rehabilitation programmes in terms of maintaining or improving the physical and psychosocial well-being of adult cancer survivors. It was possible to pool the results of studies statistically for one outcome measure (SF-36) which was employed in only six of the 12 studies. Furthermore, one of these six studies (Giesler 2005) presented the mean change score rather than mean values at each time point. Although we requested the raw data this was not provided by the author. As a result, the main statistical finding in this review is based on data from only $29 \%$ (474 out of 1669) of the participants recruited in the 12 studies.

The studies included in this review recruited predominantly participants with prostate $(\mathrm{n}=876)$ and breast cancer $(\mathrm{n}=$ 683). This equated to $94 \%$ of the total population of participants investigated and thus there is little evidence regarding the use of multidimensional rehabilitation programmes with other cancer populations. The gender split of participants recruited ( $M=938, F$ $=793$ ) equates with national statistics on the proportion of male to female cancer incidence (CRUK, 2011). In relation to age, the majority of people diagnosed with cancer are over 65 years of age; conversely, only four studies in this review (Berglund 2007; Carmack Taylor 2006; Daubenmier 2006; Demark-Wahnefried 2006) had participants with a mean age over 65 years. The majority of studies comprised participants who were well educated or from higher social classes. The under representation of older participants, people with lower educational levels or those from less affluent backgrounds limits the generalisability of the findings.

This review has highlighted that a wide range of interventions have been developed to aid the rehabilitation of adult cancer survivors. This diversity limits our ability to provide conclusive evidence regarding the relative benefits of different interventions. Considerable disparity was identified regarding 'standard services' for adult cancer survivors. In the majority of countries 'standard' care does not appear to involve any form of organised rehabilitation, unlike Germany where cancer survivors receive an intensive short-term rehabilitation programme; this information was obtained through correspondence with one of the authors of a paper considered for inclusion (Heim 2007). As this model of care differs considerably from elsewhere the two German studies (Hartmann 2007; Heim 2007) were excluded from the review (see Characteristics of excluded studies). Many of the studies considered in this review provided minimal information about the interventions provided. Future studies should provide a clear description of the intervention(s) in order to facilitate analytic comparisons and data synthesis. Descriptions should include detailed information about behaviour change techniques (e.g. the provision of factual information or motivational interviewing) and should, where possible, include precise standardised descriptions (Abraham 2008) to allow future replication and testing.

The range of outcome measures used also limited our ability to conduct pooled analyses and make firm conclusions regarding the effectiveness of rehabilitation programmes for this group of patients. Secondary outcomes for this review included adherence, satisfaction and adverse outcomes; however, these outcomes were not widely reported. Furthermore, it should be highlighted that no information on the cost of the rehabilitation programmes, or other resource implications, was provided in any of the studies.

\section{Quality of the evidence}

We rated none of the studies included as having a low risk of bias. However, nine studies (Bai 2004; Carmack Taylor 2006; Daubenmier 2006; Demark-Wahnefried 2006; Fillion 2008; Giesler 2005; Lepore 1999; May 2008a; Rogers 2009) provided insufficient information about the criteria required to make a judgement about risk of bias. Selection bias did not appear to be an issue in these studies although there was scope for better reporting of the methods of participant selection. Domains where a high risk of bias was identified were minimal. Two studies contained evidence of selective reporting in one (Berglund 2007) or two outcome measures (Demark-Wahnefried 2007). Two studies did not blind the outcome assessor(s) (Bennett 2007; Rogers 2009) and one study had a high risk of attrition bias (Berglund 2007) due to inconsistent drop out across the groups. Although not directly leading to bias other quality indicators included the validity of the measurement tools and the assessment of precision, including sample size and the inclusion of a power calculation. Issues relating to sample size were identified in six studies - studies had a small sample size, did not report a sample size calculation (Bai 2004; Bennett 2007; Lepore 1999) or did not achieve the required sample size (Carmack Taylor 2006; Demark-Wahnefried 2006; Giesler 2005).

Included studies used established, validated psychosocial tools. The assessment of physical activity was based on self report in the majority of the studies. The accuracy of these measures may be affected by social desirability or poor recall (Davies 2010; Rogers 2009). In addition, they may be influenced by mood, misjudgement or misinterpretation by an individual and thus it has been recommended that interpretation of physical outcomes should not be based solely on self report measures (Louie 2010). Participants in the intervention and control groups completed the same self report measures, and so it is likely that any systematic biases were distributed evenly. Only six studies used objective measurements to test physical change; these included a six-minute walk test (Bennett 2007; Carmack Taylor 2006; Demark-Wahnefried 2006), treadmill (Fillion 2008; Rogers 2009) and muscle strength (May 2008a; Rogers 2009). Greater use of these measures or the use of pedometers and/or accelerometers to validate self reported exercise behaviour should be explored in future research. 
Despite the vast amount of literature relating to the rehabilitation of cancer survivors, only a small number of RCTs of interventions combining physical and psychosocial domains were identified (12 studies, 1669 participants). This small body of evidence, the inherent diversity in the interventions and outcomes as well as the limitations outlined above should be borne in mind when considering the findings of this review.

\section{Potential biases in the review process}

This Cochrane review employed a highly sensitive search strategy to ensure a broad range of rehabilitation interventions and cancer diagnoses. The process of identifying and synthesising studies is more challenging when studies generate multiple publications from the same study. In this review, single studies were reported in more than one paper with one study reporting findings in four discrete publications (Korstjens 2008; May 2008a; May 2009; van Weert 2010). The use of a highly sensitive search strategy posed significant challenges in relation to the identification of studies for inclusion and the assessment and assimilation of the available evidence. However, the approach is inclusive and it has been used successfully in the study of rehabilitation for other disease groups, such as stroke. It is important to note that despite this inclusive approach some groups were excluded, such as studies which recruited very specific subgroups of patients, e.g. obese endometrial patients.

Due to the vast amount of literature identified in the initial search strategy, grey literature such as dissertation theses and conference abstracts were excluded. As we were interested in studies that were randomised or quasi-randomised and completed to the highest standards, only research that was published in peer-reviewed journals was included in the review. This approach may have introduced a degree of publication bias in the review though internet searches, checking reference lists and contacts with experts in the field failed to identify additional high-quality studies which met our inclusion criteria.

The review was limited to rehabilitation programmes designed for patients who had completed their primary treatment. Programmes that were conducted during primary treatment were excluded as many of these programmes focused on overcoming treatmentrelated problems and we wanted to consider programmes that prepared patients for life after treatment and living with cancer as a chronic disease. The motivation behind the selection of this criterion was the currently changing models of follow-up care, whereby fewer patients will receive their long-term followup or reviews in hospital and instead will be prepared to cope with the long-term consequences of their disease independently. This factor may have influenced the recruitment and attrition problems experienced by many of the studies, as it is proposed that the 'teachable moment' (Demark-Wahnefried 2005) for cancer survivors is close to diagnosis and treatment and as time passes receptiveness and motivation to change lifestyles diminishes.

\section{Agreements and disagreements with other studies or reviews}

Rehabilitation programmes have been proven to be beneficial for other chronic diseases such as heart disease (Jolliffe 2001), multiple sclerosis (Khan 2008) and chronic obstructive pulmonary disease (Lacasse 2006). In addition, previous reviews on single interventions such as exercise (Fong 2012; Speck 2010;
Spence 2010) or psychological therapies (Edwards 2008) have shown positive outcomes for patients with cancer. Therefore, it would appear reasonable to assume that combining physical and psychological interventions together in a multidimensional rehabilitation programme would produce added value or benefits for patients. The findings of this review and a similar review (Mewes 2012) do not support this strategy. Overall, the addition of a psychosocial component had a limited effect, though it should be noted that the quality of the studies was generally poor. This review also suggests that programmes of a long duration do not convey additional benefits over shorter duration (less than six months) programmes. This finding concurs with a similar review (Mewes 2012) and a review which looked specifically at self management interventions for prostate cancer survivors (Cockle-Hearne 2010).

\section{AUTHORS' CONCLUSIONS}

\section{Implications for practice}

Multidimensional rehabilitation programmes (MDRPs) are complex and multi-faceted interventions and due to the small body of research evidence currently available, practice recommendations are limited. Tentatively, this review suggests that MDRPs may have positive physical benefits for adult cancer survivors. In particular, programmes with a uni-dimensional focus appear to be more successful in terms of generating a positive change in the area related to their focus. Cancer site-specific programmes do not have any advantage over programmes designed for participants with mixed cancer diagnoses. Available evidence suggests that face-toface delivery, supplemented with at least one follow-up telephone call, may be the most effective mode of intervention delivery. There is no evidence to support the development of rehabilitation programmes conducted over prolonged periods or with multiple contacts; there is no evidence to suggest a difference in outcome depending on the type of health professional delivering the intervention. Urging caution about the findings, service providers may benefit from giving attention to the development of short, focused rehabilitation programmes or sessions that patients could choose based on the match or 'fit' with their specific needs.

\section{Implications for research}

Due to the small number of high-quality studies in this area, the main lessons from this review relate to the need for future research in this area. There is a need for further large randomised controlled trials (RCTs) to test the effectiveness of MDRPs in clinical practice. RCTs control for unknown confounding factors of which there are many in rehabilitation (Turner-Stokes 2005). Studies should include power calculations to ensure adequate sample sizes and strategies to allow for attrition and to ensure recruitment targets are achieved. In addition, assessor blinding should be incorporated and there is a need for uniformity in outcome measures that will facilitate meta-analyses. It would be beneficial to use validated methods to assess physical functioning outcomes using either exercise tests or pedometers/accelerometers instead of self reported physical activity. Due to the tightening financial constraints currently being faced by many healthcare systems, there is an overwhelming need to identify the cost-benefits of new interventions over conventional care for survivors. 


\section{ACK N O WLEDGEMENTS}

Alex Mcllroy, Librarian, The Medical Library, Queen's University Belfast, Belfast, Northern Ireland.
Richard Fallis, Librarian, The Medical Library, Queen's University Belfast, Belfast, Northern Ireland.

Jane Hayes, Cochrane Gynaecological Cancer Group for her assistance in developing the search strategy.

Clare Jess, Cochrane Gynaecological Cancer Group for her support, advice and patience throughout this review. 


\section{RE F E R E N C E S}

\section{References to studies included in this review}

Bai 2004 \{published data only\}

Bai S, Ma C, Liu Y, Xue W, Luo M, Ou Z. Effects of cognitive behavior intervention and cinesiateics on the quality of life of patients with nasopharyngeal carcinoma after radiotherapy. Chinese Journal of Clinical Rehabilitation 2004;8(29):6312-3.

\section{Bennett 2007 \{published data only\}}

Bennett JA, Lyons KS, Winters-Stone K, Nail LM, Scherer J. Motivational interviewing to increase physical activity in longterm cancer survivors. Nursing Research 2007;56(1):18-27.

\section{Berglund 2007 \{published data only\}}

Berglund G, Petersson LM, Eriksson KC, Wallenius I, Roshanai A, Nordin KM, et al. "Between Men": a psychosocial rehabilitation programme for men with prostate cancer. Acta Oncologica 2007;46(1):83-9.

\section{Carmack Taylor 2006 \{published data only\}}

Carmack Taylor CL, Demoor C, Smith MA, Dunn AL, BasenEngquist K, Nielsen I, et al. Active for life after cancer: a randomized trial examining a lifestyle physical activity program for prostate cancer patients. Psycho-Oncology 2006;15(10):847-62.

\section{Daubenmier 2006 \{published data only\}}

Daubenmier JJ, Weidner G, Marlin R, Crutchfield L, et al. Lifestyle and health related quality of life of men with prostate cancer managed with active surveillance. Urology 2006;67(1):125-130.

\section{Demark-Wahnefried 2006 \{published data only\}}

Demark-Wahnefried W, Clipp EC, Morey MC, Pieper CF, Sloane R, Snyder DC, et al. Lifestyle intervention development study to improve physical function in older adults with cancer: outcomes from Project LEAD. Journal of Clinical Oncology 2006;24(21):3465-73.

\section{Demark-Wahnefried 2007 \{published data only\}}

Demark-Wahnefried W, Clipp EC, Lipkus IM, Lobach D, Snyder DC, Sloane R, et al. Main outcomes of the FRESH START Trial: a sequentially tailored, diet and exercise mailed print intervention among breast and prostate cancer survivors. Journal of Clinical Oncology 2007;25(19):2709-18.

\section{Fillion 2008 \{published data only\}}

Fillion L, Gagnon P, Leblond F, Gelinas C, Savard J, Dupuis R, et al. A brief intervention for fatigue management in breast cancer survivors. Cancer Nursing 2008;31(2):145-59.

\section{Giesler 2005 \{published data only\}}

Giesler RB, Given B, Given RW, Rawl S, Monaghan P, Burns B, et al. Improving the quality of life of patients with prostate carcinoma: a randomized trial testing the efficacy of a nursedriven intervention. Cancer 2005;104(4):752-62.
Lepore 1999 \{published data only\}

Lepore SJ, Helgeson VS. Psychoeducational support group enhances quality of life after prostate cancer. Cancer Research Therapy and Control 1999;8(1-2):81-91.

May 2008a \{published data only\}

Korstjens I, May AM, van Weert E, Mesters I, Tan F, Ros WJG, et al. Quality of life after self-management cancer rehabilitation: a randomized controlled trial comparing physical and cognitivebehavioral training versus physical training. Psychosomatic Medicine 2008;70(4):422-9.

May AM, Korstjens I, van Weert E, van den Borne B, HoekstraWeebers $\mathrm{J}$, et al. Long-term effects on cancer survivors' quality of life of physical training versus physical training combined with cognitive behavioral therapy: results from a randomised trial. Supportive Care in Cancer 2009;17(6):653-63.

* May AM, van Weert E, Korstjens I, Hoekstra-Weebers JEHM, Van Der Schans CP, Zonderland ML, et al. Improved physical fitness of cancer survivors: a randomised controlled trial comparing physical training with physical and cognitivebehavioural training. Acta Oncologica 2008;47(5):825-34.

van Weert E, May AM, Korstjens I, Post WJ, van der Schans CP, van den Borne B, et al. Cancer-related fatigue and rehabilitation: a randomised controlled multi-centre trial comparing physical training combined with cognitive behavioral therapy with physical training only and with no intervention.. Physical Therapy 2010;90:1413-25.

Rogers 2009 \{published data only\}

Rogers LQ, Hopkins-Price P, Vicari S, Pamenter R, Courneya KS, Markwell S, et al. A randomised trial to increase physical activity in breast cancer survivors. Medicine and Science in Sport and Exercise 2009;41(4):935-46.

\section{References to studies excluded from this review}

Berglund 1994 \{published data only\}

Berglund G, Bolund C, Gustafsson U-L, Sjoden P-O. A randomized study of a rehabilitation program for cancer patients: the 'Starting again' group. Psycho-Oncology 1994;3(2):109-20.

\section{Bloom 2008 \{published data only\}}

Bloom JR. Addressing the needs of young breast cancer survivors at the 5 year milestone: can a short-term, low intensity intervention produce change?. Journal of Cancer Survivorship 2008;2(3):190-240.

\section{Cain 1986 \{published data only\}}

Cain EN, Kohorn El, Quinlan DM, Latimer K, Schwartz PE. Psychosocial benefits of a cancer support group. Cancer 1986;57:183-9. 
Cho 2006 \{published data only\}

Cho O-H, Yoo Y-S, Kim N-C. Efficacy of comprehensive group rehabilitation for women with early breast cancer in South Korea. Nursing and Health Sciences 2006;8(3):140-6.

\section{Courneya 2003 \{published data only\}}

Courneya KS, Friedenreich CM, Sela RA, Quinney HA, Rhodes RE, Handman M. The group psychotherapy and home-based physical exercise (Group-Hope) trial in cancer survivors: physical fitness and quality of life outcomes. Psycho-Oncology 2003;12(4):357-74.

\section{Cunningham 1989 \{published data only\}}

Cunningham AJ, Tocco EK. A randomized trial of group psychoeducational therapy for cancer patients. Patient Education and Counselling 1989;14(2):101-14.

\section{Fan 2006 \{published data only\}}

Fan J-C, He X-M, Li J-Y. Effects of combined interventional treatment on quality of life in patients with nasopharyngeal carcinoma. Chinese Journal of Clinical Rehabilitation 2006;10(20):16-8.

\section{Hartmann 2007 \{published data only\}}

Hartmann U, Muche R, Reuss-Borst M. Effects of a step-by-step inpatient rehabilitation programme on quality of life in breast cancer patients. a prospective randomised study. Onkologie 2007;30(4):177-82.

\section{Heim 2007 \{published data only\}}

Heim ME, v d Malsburg ML, Niklas A. Randomized controlled trial of a structured training program in breast cancer patients with tumor-related chronic fatigue. Onkologie 2007;30(8-9):429-34.

\section{Johansson 2008 \{published data only\}}

Johansson B, Brandberg Y, Hellbom M, Persson C, Petersson LM, Berglund $G$, et al. Health related quality of life in cancer patients: results of a large randomised study. British Journal of Cancer 2008;99(12):1975-83.

\section{van Weert 2005 \{published data only\}}

van Weert E, Hoekstra-Weebers J, Grol B, Otter R, Arendzen HJ, Postema K, et al. A multidimensional cancer rehabilitation program for cancer survivors: effectiveness on healthrelated quality of life. Journal of Psychosomatic Research 2005;58(6):485-96.

\section{Zhang Tong 2005 \{published data only\}}

Zhang T, Chang X-M, He Y-G, Huang H-X, Fan K-S. Effects of rehabilitation therapy in relieving pain and improving quality of life in patients with advanced cancer. Chinese Journal of Clinical Rehabilitation 2005;9(40):59-61.

\section{Additional references}

\section{Abraham 2008}

Abraham C, Michie S. A taxonomy of behavior change techniques used in interventions. Health Psychology 2008;27(3):379-87.

\section{Aziz 2002}

Aziz N. Cancer survivorship research: challenge and opportunity. Journal of Nutrition 2002;132(Suppl 11):3494S-503S.

\section{Aziz 2003}

Aziz NM, Rowland JH. Trends and advances in cancer survivorship research: challenge and opportunity. Seminars in Radiation Oncology 2003;13(3):248-66.

\section{Berglund 2003}

Berglund G, Petersson LM, Eriksson KR, Haggman M. "Between Men": patient perceptions and priorities in a rehabilitation program for men with prostate cancer. Patient Education \& Counseling 2003;49(3):285-92.

\section{Bultz 2008}

Bultz BD, Carlson LE. Emotional distress: the sixth vital sign in cancer care. Journal of Clinical Oncology 2008;15(2):93-5.

\section{Cancer Reform Strategy 2007}

Department of Health. Cancer Reform Strategy. www.dh.gov.uk/ en/Healthcare/NationalServiceFrameworks/Cancer/index.htm 2007.

\section{Cardy 2006}

Cardy P, Corner J, Evans J. Worried Sick: The Emotional Impact of Cancer. London: Macmillan Cancer Support, 2006.

\section{Carmack 2004}

Carmack Taylor CL, Smith MA, de Moor C, Dunn AL, Pettaway C, Sellin R, et al. Quality of life intervention for prostate cancer patients: design and baseline characteristics of the active for life after cancer trial. Controlled Clinical Trials 2004;25(3):265-85.

\section{Carmack 2007}

Carmack Taylor CL, de Moor C, Basen-Engquist K, Smith MA, Dunn AL, Badr H, et al. Moderator analyses of participants in the active for life after cancer trial: implications for physical activity group intervention studies. Annals of Behavioral Medicine 2007;33(1):99-104.

\section{Cockle-Hearne 2010}

Cockle-Hearne J, Faithfull S. Self-management for men surviving prostate cancer: a review of behavioural and psychosocial interventions to understand what strategies can work, for whom and in what circumstances. Psycho-oncology 2010;19(9):909-22.

\section{Corner 2007}

Corner J, Richardson A. Cancer Survivorship Briefing Paper. http://www.macmillan.org.uk/Documents/GetInvolved/ Campaigns/Campaigns/campaignsupdate/Cancer_ survivorship_paper.pdf 2007.

\section{Cramp 2012}

Cramp F, Daniel J. Exercise for the management of cancerrelated fatigue in adults. Cochrane Database of Systematic Reviews 2012, Issue 11. [DOI: 10.1002/14651858.CD006145] 


\section{CRUK 2008}

Cancer Research UK. Cancer Survival Rates for Patients Diagnosed 1996-1999. www.cancerresearchuk.org/cancerstats/ survival/latestrates (accessed September 2008).

\section{CRUK, 2011}

Cancer Research UK. Cancer Incidence Statistics. http:// info.cancerresearchuk.org/prod_consump/groups/cr common/@nre/@sta/documents/generalcontent/crukmig_ 1000ast-2737.xls 2011.

\section{Davies 2010}

Davies P, Taylor F, Beswick A, Wise F, Moxham T, Rees K, et al. Promoting patient uptake and adherence in cardiac rehabilitation. Cochrane Database of Systematic Reviews 2010, Issue 7. [DOI: 10.1002/14651858.CD007131]

\section{De Boer 2011}

de Boer AGEM, Taskila T, Tamminga SJ, Frings-Dresen MHW, Feuerstein M, Verbeek JH. Interventions to enhance returnto-work for cancer patients. Cochrane Database of Systematic Reviews 2011, Issue 2. [DOI: 10.1002/14651858.CD007569]

\section{Demark-Wahnefried 2003}

Demark-Wahnefried W, Clipp EC, McBride C, Lobach DF, Lipkus I, Peterson B, et al. Design of FRESH START: a randomized trial of exercise and diet among cancer survivors. Medicine and Science in Sports and Exercise 2003;35(3):415-24.

\section{Demark-Wahnefried 2003a}

Demark-Wahnefried W, Morey MC, Clipp EC, Pieper CF, Snyder DC, Sloane R, et al. Leading the way in exercise and diet (project lead): intervening to improve function among older breast and prostate cancer survivors. Controlled Clinical Trials 2003;24(2):206-3.

\section{Demark-Wahnefried 2005}

Demark-Wahnefried W, Aziz NM, Rowland JH, Pinto BW. Riding the crest of the teachable moment: promoting long-term health after the diagnosis of cancer. Journal of Clinical Oncology 2005;23(24):5814-30.

\section{Edwards 2008}

Edwards AGK, Hulbert-Williams N, Neal RD. Psychological interventions for women with metastatic breast cancer. Cochrane Database of Systematic Reviews 2008, Issue 3. [DOI: 10.1002/14651858.CD004253]

\section{Fawzy 1993}

Fawzy FI, Fawzy NW, Hyun CS, Elashoff R, Guthrie D, Fahey JL. Malignant melanoma: effects of an early structured psychiatric intervention, coping and affective state on recurrence and survival 6 years later. Archives of General Psychiatry 1993;50:681-9.

\section{Fong 2012}

Fong D, Ho JW, Hui BP, Lee AM, Macfarlane DJ, Leung SS, et al. Physical activity for cancer survivors: meta-analysis of randomised controlled trials. BMJ 2012;344:doi: 10.1136/ bmj.e70.

\section{Fors 2011}

Fors EA, Bertheussen GF, Thune I, Juvet LK, Elvaas IK, Oldervoll L, et al. Psychosocial interventions as part of breast cancer rehabilitation programs? Results from a systematic review. Psycho-Oncology 2011;20(9):909-18.

\section{Frattaroli 2008}

Frattaroli J, Weidner G, Dnistrian AM, Kemp C, et al. Clinical events in prostate cancer lifestyle trial: results from two years follow-up. Urology 2008;72(6):1319-1323.

\section{Galway 2012}

Galway K, Black A, Cantwell M, Cardwell C, Mills M, Donnelly M. Psychosocial interventions to improve quality of life and emotional wellbeing for recently diagnosed cancer patients. Cochrane Database of Systematic Reviews 2012, Issue 11. [DOI: 10.1002/14651858.CD007064.pub2]

\section{Hewitt 2006}

Hewitt M, Ganz PA. From Cancer Patient to Cancer Survivor: Lost in Transition. Washington, D.C.: The National Academies Press, 2006.

\section{Higgins 2011}

Higgins JPT, Green S (editors). Cochrane Handbook for Systematic Reviews of Interventions Version 5.1.0 [updated March 2011]. The Cochrane Collaboration, 2011. Available from www.cochrane-handbook.org.

\section{Hodges 2011}

Hodges LJ, Walker J, Kliboer AM, Ramirez AJ, Richardson A, Velikova $\mathrm{G}$, et al. What is a psychological intervention? A meta-review and practical proposal. Psycho-Oncology 2011;20(5):470-8.

\section{Jefford 2008}

Jefford M, Karahalios E, Pollard A, Baravelli C, Carey M, Franklin J, et al. Survivorship issues following treatment completion - results from focus groups with Australian cancer survivors and health professionals. Journal of Cancer Survivorship 2008;2:20-32.

\section{Jolliffe 2001}

Jolliffe JA, Rees K, Taylor RS, Thompson D, Oldridge N, Ebrahim S. Exercise-based rehabilitation for coronary heart disease. Cochrane Database of Systematic Reviews 2001, Issue 1. [DOI: 10.1002/14651858.CD001800]

\section{Khan 2008}

Khan F, Ng L, Turner-Stokes L. Effectiveness of vocational rehabilitation intervention on the return to work and employment of persons with multiple sclerosis. Cochrane Database of Systematic Reviews 2009, Issue 1. [DOI: 10.1002/14651858.CD007256]

\section{Korstjens 2008}

Korstjens I, May AM, van Weert E, Tan F, et al. Quality of life after self-management cancer rehabilitation: a randomised controlled trial comapring physical and cognitive-behavioral training versus physical training. Psychosomatic Medicine 2008;70(4):422-429. 


\section{Lacasse 2006}

Lacasse Y, Goldstein R, Lasserson TJ, Martin S. Pulmonary rehabilitation for chronic obstructive pulmonary disease. Cochrane Database of Systematic Reviews 2006, Issue 2. [DOI: 10.1002/14651858.CD003793]

\section{Louie 2010}

Louie GH, Ward MM. Association of measured physical performance and demographic and health characteristics with self-reported physical function: implications for the interpretation of self-reported limitations. Health and Quality of Life Outcomes 2010;8:84.

\section{Markes 2006}

Markes M, Brockow T, Resch KL. Exercise for women receiving adjuvant therapy for breast cancer. Cochrane Database of Systematic Reviews 2006, Issue 4. [DOI: 10.1002/14651858.CD005001]

\section{May 2008b}

May AM, Duivenvoorden HJ, Korstjens I, van Weert E, HoekstraWeebers J, van den Borne B, et al. The effect of group cohesion on rehabilitation outcome in cancer survivors. Psycho-Oncology 2008;17(9):917-25.

\section{May 2009}

May AM, Korstjens I, van Weert E, van den Borne B, et al. Longterm effects on cancer survivors' quality of life of of ohysical training versus physical training combined with cognitive behavioral therapy: results from a randomised trial.. Supportive Care in Cancer 2009;17(6):653-663.

\section{Mewes 2012}

Mewes JC, Steuten LM, ljzerman MJ, van Harten WH. Effectiveness of multidimensional cancer survivor rehabilitation and cost effectiveness of cancer rehabilitation in general: a systematic review. The Oncologist 2012;17(12):1581-93.

\section{Mosher 2008}

Mosher CE, Fuemmeler BF, Sloane R, Kraus WE, Lobach DF, Snyder DC, et al. Change in self-efficacy partially mediates the effects of the fresh start intervention on cancer survivors' dietary outcomes. Psycho-Oncology 2008;17(10):1014-23.

\section{NCCS 2009}

NCCS. National Coalition for Cancer Survivorship. http:// www.canceradvocacy.org/ 2009.

\section{$\mathrm{NCl} 2004$}

National Cancer Institute. About Survivorship Research: Survivorship Definitions. http://cancercontrol.cancer.gov/ocs/ definitions.html (accessed 17 September 2008).

\section{Ornish 2005}

Ornish D, Weidner G, Fair WR, Marlin, et al. Intensive lifestyle changes may affect the progression of prostate cancer. Journal of Urology 2005;174(3):1065-1069.

\section{Pettigrew 2006}

Pettigrew M, Roberts H. Systematic Reviews in the Social Sciences: A Practical Guide. Oxford: Blackwell, 2006.

\section{RevMan 2011 [Computer program]}

The Nordic Cochrane Centre, The Cochrane Collaboration. Review Manager (RevMan). Version 5.1. Copenhagen: The Nordic Cochrane Centre, The Cochrane Collaboration, 2011.

\section{Roper 1987}

Roper N. Pocket Medical Dictionary. 14th Edition. Edinburgh: Churchill Livingstone, 1987.

\section{Schroevers 2006}

Schroevers M, Ranchor AV, Sanderman R. Adjustment to cancer in the 8 years following diagnosis: a longitudinal study comparing cancer survivors with healthy individuals. Social Science and Medicine 2006;63(6):598-610.

\section{Schultz 2003}

Schultz PN, Beck ML, Stava C, Vassilopoulou-Sellin R. Health profiles in 5,836 long-term cancer survivors. International Journal of Cancer 2003;104(4):488-95.

\section{Snyder 2008}

Snyder DC, Sloane R, Lobach D, Lipkus P, Peterson B, Kraus W, et al. Differences in baseline characteristics and outcomes at 1- and 2-year follow-up of cancer survivors accrued via selfreferral versus cancer registry in the FRESH START Diet and exercise trial. Cancer Epidemiology, Biomarkers \& Prevention 2008;17(5):1288-94.

\section{Speck 2010}

Speck RM, Courneya KS, Masse LC, Duval S, Schmitz KH. An update of controlled physical activity trials in cancer survivors: a systematic review and meta-analysis. Journal of Cancer Survivorship 2010;4(2):87-100.

\section{Spence 2010}

Spence RR, Heesch KC, Brown WJ. Exercise and cancer rehabilitation: a systematic review. Cancer Treatment Reviews 2010;36(2):185-94.

\section{Turner-Stokes 2005}

Turner-Stokes L, Nair A, Sedki I, Disler PB, Wade DT. Multidisciplinary rehabilitation for acquired brain injury in adults of working age. Cochrane Database of Systematic Reviews 2005, Issue 3. [DOI: 10.1002/14651858.CD004170]

\section{van Weert 2010}

van Weert E, May A, Korstjens, et al. Cancer-related fatigue and rehabilitation: a randomised controlled multi-centre trial comparing physical training combined with cognitive behavioral therapy with physical training only and with no intervention. Physical therapy 2010;90:1413-1425.

\section{Ware 1993}

Ware JE, Snow KK, Kosinski M, Gandek B. SF-36 Health Survey Manual and Interpretation Guide. Boston: New England Medical Centre, 1993.

* Indicates the major publication for the study 


\section{CHARACTERISTICS OF STUDIES}

\section{Characteristics of included studies [ordered by study ID]}

\section{Bai 2004}

\begin{tabular}{ll}
\hline Methods & Randomised controlled study \\
& Intention-to-treat analyses used \\
& Loss to follow-up: unclear \\
\hline Participants & 45 participants (I: $24 / \mathrm{C}: 21)$ \\
Cancer sites: nasopharyngeal $100 \%$ \\
Mean age (I: 49.2 years/C: 50.3 years) \\
Post-treatment: all patients had received radiotherapy prior to study \\
Country: China
\end{tabular}

A CBT and exercise intervention to explore the effects on improving QoL
Contact and duration: number of contacts unclear-possibly over a 3-month period
Physical component: exercise activities with low to moderate intensity were set out for each patient.
They were required to exercise regularly and do physical training every day.
Psychosocial component: an educational psychological intervention to provide information on treat-
ment, prognosis, complications and rehabilitation. As well as information on different coping methods,
encouragement to develop new life values, reduce tension and build a positive life attitudes and set
hopes for the future. Relaxation training was also given.

Assessed at: 3 months after radiotherapy
Physical: EORTC-C30 - physical function
Psychosocial: EORTC-C30 - role function, social function, emotional function, cognitive function, social
function, physiological symptoms, general QoL

Notes

\section{Risk of bias}

\begin{tabular}{lll}
\hline Bias & Authors' judgement & Support for judgement \\
\hline $\begin{array}{l}\text { Random sequence genera- } \\
\text { tion (selection bias) }\end{array}$ & Unclear risk & RCT - sequence generation not mentioned \\
\hline $\begin{array}{l}\text { Allocation concealment } \\
\text { (selection bias) }\end{array}$ & Unclear risk & Not mentioned \\
\hline $\begin{array}{l}\text { Blinding (performance } \\
\text { bias and detection bias) } \\
\text { All outcomes }\end{array}$ & Unclear risk & Not mentioned \\
\hline
\end{tabular}


Bai 2004 (Continued)

Selective reporting (re- $\quad$ Low risk $\quad$ All outcomes reported in results
porting bias)

Other bias Low risk None identified

\section{Bennett 2007}

\begin{tabular}{ll}
\hline Methods & A prospective RCT \\
Intention-to-treat analyses used \\
Loss to follow-up: numbers and reasons in flow chart
\end{tabular}

Participants
Cancer sites: breast (I: 20/C: 23), other cancers (8/6)
Mean age: (I: 55.5 years/C: 60.1 years)
Post-treatment: all patients had completed treatment at least 6 months prior to study
Country: New Zealand

Interventions

A motivational interviewing $(\mathrm{MI})$ intervention to increase physical activity and improve aerobic fitness, health and fatigue in cancer survivors compared a control group

Contact and duration: $\mathrm{Ml}$ at enrolment ( 30 minutes) +3 telephone calls ( 20 minutes each) at 2 weeks, 2 and 4.5 months. Control group received no interview, only 2 telephone calls at 2 and 4.5 months to arrange 3 and 6-month outcomes.

Physical component: intervention group encouraged to achieve 30 minutes of moderate activity on most days of the week

Psychosocial component: identify barriers to exercise, build self efficacy and problem solving

$\begin{array}{ll}\text { Outcomes } & \text { Assessed at BL, } 3 \text { and } 6 \text { months } \\ & \text { Physical: CHAMPS Physical activity questionnaire, 6-minute walk test, SF-36 PCS score, Schwartz Can- } \\ \text { cer Fatigue Scale } & \\ & \text { Psychosocial: SF-36 MCS score, self efficacy for physical activity }\end{array}$

Notes

\section{Risk of bias}

\begin{tabular}{lll}
\hline Bias & Authors' judgement & Support for judgement \\
\hline $\begin{array}{l}\text { Random sequence genera- } \\
\text { tion (selection bias) }\end{array}$ & Low risk & RCT "computer generated randomisation scheme" \\
\hline $\begin{array}{l}\text { Allocation concealment } \\
\text { (selection bias) }\end{array}$ & Low risk & "Assignments were placed in sealed envelopes prior to study" \\
\hline $\begin{array}{l}\text { Blinding (performance } \\
\text { bias and detection bias) } \\
\text { All outcomes }\end{array}$ & High risk & "The physical activity counsellor conducted the intervention and outcome mea- \\
& & surements and was not blinded to group assignment" \\
\hline
\end{tabular}


Bennett 2007 (Continued)

Incomplete outcome data Low risk Loss to follow-up: numbers and reasons in flow chart

(attrition bias)

All outcomes

$\begin{aligned} & \text { Selective reporting (re- } \\ & \text { porting bias) }\end{aligned} \quad$ Low risk All outcomes listed are reported at baseline, 3 and 6 months in Table 2

\begin{tabular}{ll}
\hline Other bias $\quad$ Low risk $\quad$ None identified \\
\hline
\end{tabular}

Berglund 2007

$\begin{array}{ll}\text { Methods } & \text { RCT } \\ & \text { Analyses based on intention-to-treat } \\ & \text { Loss to follow-up: numbers and reasons given in flow-chart } \\ & 211 \text { participants (Phys: } 53 / \text { Info: } 55 / \text { Physlnfo: } 52 / C: 51) \\ & \text { Cancer sites: prostate } 100 \% \\ \text { Participants } & \text { Mean age: } 69 \text { years } \\ & \text { Post-treatment: recruited within } 6 \text { months of diagnosis(N.B. } 10 \% \text { of participants received radiotherapy } \\ \text { - unclear if this was completed prior to study) } & \text { Country: Sweden }\end{array}$

'Between Men', a psychosocial rehabilitation programme
Contact and duration:
Assigned to 1 of 4 groups: physical training alone (Phys), information alone (Info), physical training plus
information (PhysInfo) or a standard care control group (C)
Phys: 7 sessions: 60 -minute physical training with movement and fitness training, relaxation, breathing
and pelvic floor exercises. Discussion was encouraged.
Info: 7 sessions: 60 -minute information sessions on information about cancer, treatment, side effects
and reactions to crisis. Discussion was encouraged.
Psychlnfo: 7 sessions: 135 minutes of Phys + Info combined

\begin{tabular}{ll}
\hline Outcomes & EORTC QLQ-C30 (all sub-scales); HADS \\
\hline Notes & $10 \%$ of patients received radiotherapy - unclear if this was prior to intervention \\
\hline
\end{tabular}

\section{Risk of bias}

\begin{tabular}{lll}
\hline Bias & Authors' judgement & Support for judgement \\
\hline $\begin{array}{l}\text { Random sequence genera- } \\
\text { tion (selection bias) }\end{array}$ & Unclear risk & RCT "stratification on stage, curative treatment and age" \\
\hline $\begin{array}{l}\text { Allocation concealment } \\
\text { (selection bias) }\end{array}$ & Unclear risk & Not mentioned \\
\hline $\begin{array}{l}\text { Blinding (performance } \\
\text { bias and detection bias) }\end{array}$ & Unclear risk & Not mentioned \\
\hline
\end{tabular}


Berglund 2007 (Continued)

All outcomes

$\begin{array}{ll}\begin{array}{l}\text { Incomplete outcome data } \\ \text { (attrition bias) }\end{array} & \text { High risk } \\ \text { All outcomes } & \text { High loss to follow-up. } 211 \text { recruited, only } 158 \text { in final sample } \\ & \text { Loss to follow-up uneven across the groups }\end{array}$

Selective reporting (re- High risk
porting bias)

EORTC outcome data at 12 months not provided for each group, as HRQOL did not change by intervention or time. Instead HRQOL data given for those with and without metastases.

Other bias Low risk None identified

$\begin{array}{ll}\text { Methods } & \text { Randomised controlled trial } \\ & \text { Intention-to-treat analysis not used } \\ \text { Loss to follow-up: numbers in flow-chart; reasons in text }\end{array}$

Participants
Cancer sites: prostate $100 \%$
Mean age: 69.2 years
Post-treatment: receiving androgen-ablation therapy
Country: USA

Interventions

'Active for Life' is a 6-month group-based lifestyle activity programme compared to a group-based educational support programme and standard care

Assigned to 1 of 3 study conditions: a lifestyle programme, an educational support programme or a standard care control group.

Contact and duration: both intervention arms received 16 weekly sessions and 4 bi-weekly sessions over 6 months. Sessions were 1.5 hours each

Physical component: lifestyle programme uses CBT to adopt and maintain regular physical activity. Included brief (5 mins) periods of walking and a demonstration of stretching exercises.

Psychosocial component: educational support included facilitated group discussion and expert talks on sexuality, treatment side effects or diet

Outcomes Assessed at: BL, post-intervention (month 6), 6-month follow-up (month 12)

Physical: SF-36 physical function sub-scale, 6-minute walk test, BMI, waist-to-hip circumference ratio, 7-day physical activity recall, Stage of Motivational Readiness for Physical Activity

Psychosocial: SF-36, CES-D, STAI, BPI

\section{Notes}

\section{Risk of bias}

Bias Authors' judgement Support for judgement


Carmack Taylor 2006 (Continued)

\begin{tabular}{lll}
$\begin{array}{l}\text { Random sequence genera- } \\
\text { tion (selection bias) }\end{array}$ & Unclear risk & RCT "adaptive allocation" \\
\hline $\begin{array}{l}\text { Allocation concealment } \\
\text { (selection bias) }\end{array}$ & Unclear risk & Not mentioned \\
\hline $\begin{array}{l}\text { Blinding (performance } \\
\text { bias and detection bias) } \\
\begin{array}{l}\text { All outcomes } \\
\text { o }\end{array}\end{array}$ & Low risk & $\begin{array}{l}\text { Research staff conducting assessments were blind to the participants' study } \\
\text { programme assignment }\end{array}$ \\
\hline
\end{tabular}

\begin{tabular}{lll}
\hline $\begin{array}{l}\text { Incomplete outcome data } \\
\text { (attrition bias) } \\
\text { All outcomes }\end{array}$ & Low risk & Loss to follow-up: numbers in flow-chart; reasons in text \\
\hline $\begin{array}{l}\text { Selective reporting (re- } \\
\text { porting bias) }\end{array}$ & Low risk & All outcomes reported in results \\
\hline Other bias & Unclear risk & ITT not mentioned \\
\hline
\end{tabular}

Daubenmier 2006

\begin{tabular}{|c|c|}
\hline Methods & $\begin{array}{l}\text { A randomised controlled trial } \\
\text { Intention to treat analysis not used } \\
\text { Loss to follow-up in text }\end{array}$ \\
\hline Participants & $\begin{array}{l}93 \text { participants (I:44/C:49) } \\
\text { Cancer sites: } 100 \% \text { Prostate cancer } \\
\text { Mean age: (I:64.8 / C:66.5) } \\
\text { Post-treatment: All patients had elected not to undergo conventional treatment } \\
\text { Country: USA }\end{array}$ \\
\hline Interventions & $\begin{array}{l}\text { Description: Prostate Cancer Lifestyle Trial: A one-year intensive lifestyle change program incorporating } \\
\text { diet, exercise and stress management for men on active surveillance for prostate cancer } \\
\text { Contact \& duration: } 1 \text { week residential retreat, weekly support group + weekly phone calls for first } 3 \\
\text { months and then monthly thereafter } \\
\text { Physical component: Vegan diet with supplements, moderate aerobic exercise (walking } 3 \text { hours per } \\
\text { week) } \\
\text { Psychosocial component: Stress management techniques (gentle yoga for } 60 \text { minutes per day) and a } 1 \\
\text { hour support group once weekly }\end{array}$ \\
\hline Outcomes & $\begin{array}{l}\text { Assessed at: Baseline and } 12 \text { months } \\
\text { Physical: SF-36 Physical Health Summary (PCS), PSA } \\
\text { Psychosocial: SF- } 36 \text { Mental Health Summary (MCS), Perceived Stress Scale, Prostate Cancer Index - sex- } \\
\text { ual function subscale }\end{array}$ \\
\hline
\end{tabular}


Daubenmier 2006 (Continued)

Three intervention patients withdrew soon after beginning the intervention because they said it was too difficult to follow

\section{Risk of bias}

\begin{tabular}{lll}
\hline Bias & Authors' judgement & Support for judgement \\
\hline $\begin{array}{l}\text { Random sequence genera- } \\
\text { tion (selection bias) }\end{array}$ & Unclear risk & RCT - sequence generation not mentioned \\
\hline $\begin{array}{l}\text { Allocation concealment } \\
\text { (selection bias) }\end{array}$ & Unclear risk & Not mentioned \\
\hline $\begin{array}{l}\text { Blinding (performance } \\
\text { bias and detection bias) }\end{array}$ & Unclear risk & 'Assessment of outcomes measures was not blinded to group allocation' \\
$\begin{array}{l}\text { All outcomes } \\
\begin{array}{l}\text { Incomplete outcome data } \\
\text { (attrition bias) } \\
\text { All outcomes }\end{array}\end{array}$ & Unclear risk & Loss to follow-up data provided in text \\
\hline $\begin{array}{l}\text { Selective reporting (re- } \\
\text { porting bias) }\end{array}$ & Unclear risk & $\begin{array}{l}\text { All outcomes reported in results (SF-36 reported in Daubenmier 2006, PSA and } \\
\text { progression reported in Ornish 2005). }\end{array}$ \\
\hline \begin{tabular}{l} 
Other bias \\
\hline
\end{tabular} & Unclear risk & ITT not used \\
\hline
\end{tabular}

\section{Demark-Wahnefried 2006}

\begin{tabular}{ll}
\hline Methods & Randomised controlled trial \\
Intention-to-treat analysis used \\
Loss to follow-up: numbers in flow-chart; reasons in text \\
\hline
\end{tabular}

\section{Participants}

182 participants (I: 89/C: 93)

Cancer sites: breast (I: 51/C: 53), prostate (I: 38/C: 40)

Mean age: I: 71.5 years/C: 71.9 years

Post-treatment: within 18 months of diagnosis

Country: USA

'Project LEAD' a 6-month home-based diet and exercise intervention compared with an attention control arm receiving general health information

Contact and duration: both groups received 12 telephone calls (20 to 30 mins) over 6 months

Physical component: telephone counselling and tailored print material aimed at improving exercise and diet

Psychosocial component: uses social cognitive theory to improve diet and exercise

\section{Outcomes}

\section{Assessed at: BL, 6 months and 12 months}

Physical: Diet Quality Index, physical activity (CHAMPS), SF-36 Physical Function sub-scale, BMI, height, weight and physical function testing 
Demark-Wahnefried 2006 (Continued)

Psychosocial: FACT B/P, CES-D, Dukes Social Support Index

\section{Notes}

\section{Risk of bias}

\begin{tabular}{lll}
\hline Bias & Authors' judgement & Support for judgement \\
\hline $\begin{array}{l}\text { Random sequence genera- } \\
\text { tion (selection bias) }\end{array}$ & Unclear risk & RCT "block randomly assigned" \\
\hline $\begin{array}{l}\text { Allocation concealment } \\
\text { (selection bias) }\end{array}$ & Unclear risk & Not mentioned \\
\hline $\begin{array}{l}\text { Blinding (performance } \\
\text { bias and detection bias) } \\
\text { All outcomes }\end{array}$ & Unclear risk & Not mentioned \\
\hline $\begin{array}{l}\text { Incomplete outcome data } \\
\text { (attrition bias) } \\
\text { All outcomes }\end{array}$ & Low risk & Loss to follow-up: numbers in flow-chart; reasons in text \\
\hline $\begin{array}{l}\text { Selective reporting (re- } \\
\text { porting bias) }\end{array}$ & Low risk & All outcomes reported in results \\
\hline \begin{tabular}{l} 
Other bias \\
\hline
\end{tabular} & Low risk & None identified \\
\hline
\end{tabular}

Demark-Wahnefried 2007

\begin{tabular}{ll}
\hline Methods & Randomised controlled trial \\
& Intention-to-treat analysis used \\
& Loss to follow-up: numbers and reasons in flow-chart \\
\hline Participants & 543 participants (I: $271 / \mathrm{C}: 272)$ \\
& Cancer sites: breast (I: $153 /$ C: 153$),$ prostate (I: $118 / C: 119)$ \\
& Mean age: I: 57.0 years/C: 56.9 years \\
& Post-treatment: within 9 months of diagnosis \\
Country: USA
\end{tabular}

'FRESH START', a sequentially tailored print intervention to improve diet and exercise behaviours compared to standardised health education material

Contact and duration: postal contact only. The 10-month treatment phase involved an initial personalised workbook followed by a series of 7 individually tailored newsletters at 6-weekly intervals.

Physical component: individually tailored print material aimed at improving exercise and diet. Goals included: $150+\mathrm{min} / \mathrm{wk}$ of exercise, eating 5 or more servings of fruit and vegetables a day, restricting fat intake.

Psychosocial component: uses social cognitive theory that emphasises confidence building and skill development to improve diet and exercise 
Demark-Wahnefried 2007 (Continued)

Physical: Diet Quality Index, 7-day Physical Activity Recall (activity min/wk), 23\% sub-sample: BMI, height, weight, blood samples (lipoprotein cholesterol, C-reactive protein, insulin, interleukin-6, alpha-carotene)

Psychosocial: FACT B/P, CES-D, Dukes Social Support Index

\section{Notes}

\section{Risk of bias}

\begin{tabular}{|c|c|c|}
\hline Bias & Authors' judgement & Support for judgement \\
\hline $\begin{array}{l}\text { Random sequence genera- } \\
\text { tion (selection bias) }\end{array}$ & Low risk & RCT "random assignment lists generated using software" \\
\hline $\begin{array}{l}\text { Allocation concealment } \\
\text { (selection bias) }\end{array}$ & Low risk & $\begin{array}{l}\text { "Random assignment Implemented in a blinded fashion, at an office remote } \\
\text { from the main study office. Participants were never formally informed whether } \\
\text { they received the tailored intervention or the standardised attention control con- } \\
\text { dition." }\end{array}$ \\
\hline $\begin{array}{l}\text { Blinding (performance } \\
\text { bias and detection bias) } \\
\text { All outcomes }\end{array}$ & Low risk & $\begin{array}{l}\text { "Blinded post-study follow-up" also "Adverse events...... were categorised by a } \\
\text { committee blinded to random assignment." }\end{array}$ \\
\hline $\begin{array}{l}\text { Incomplete outcome data } \\
\text { (attrition bias) } \\
\text { All outcomes }\end{array}$ & Low risk & $\begin{array}{l}\text { Loss to follow-up: numbers and reasons in flow-chart } \\
\text { Differential drop out between study arms (6.6\% in intervention arm, } 2.2 \% \text { in at- } \\
\text { tention control arm). Although overall attrition was very low, making this less } \\
\text { of an issue } \\
\text { Low attrition rate }(4.4 \%)\end{array}$ \\
\hline $\begin{array}{l}\text { Selective reporting (re- } \\
\text { porting bias) }\end{array}$ & High risk & Risk of depression and social support not reported \\
\hline Other bias & Low risk & None identified \\
\hline
\end{tabular}

\section{Fillion 2008}

\begin{tabular}{|c|c|}
\hline \multirow[t]{3}{*}{ Methods } & $\mathrm{RCT}$ \\
\hline & Analyses based on intention-to-treat \\
\hline & Loss to follow-up: numbers given in flow-chart - no reasons given \\
\hline \multirow[t]{5}{*}{ Participants } & 94 participants (I: 48/C: 46) \\
\hline & Cancer sites: breast $100 \%$ \\
\hline & Mean age: (52.5 years) \\
\hline & $\begin{array}{l}\text { Post-treatment: recruited within } 2 \text { years of completing radiotherapy. All participants had completed } \\
\text { their treatment. }\end{array}$ \\
\hline & Country: Canada \\
\hline Interventions & $\begin{array}{l}\text { A brief group intervention that combined stress management psycho-education and physical activity } \\
\text { in reducing fatigue and improving energy levels, QoL, fitness and emotional distress compared to usual } \\
\text { care }\end{array}$ \\
\hline
\end{tabular}


Fillion 2008 (Continued)

Contact and duration: 4 weekly group meetings of 2.5 hours +1 short 'booster' telephone session

Physical component: 1 hour of supervised walking training each week

Psychosocial component: 1.5 hours of psycho-educative fatigue management each week + homebased assignments for stress/fatigue management

Outcomes

Physical: fitness: submaximal oxygen consumption ( $\left.\mathrm{Vo}_{2 \text { submax }}\right)$; single-stage treadmill walking test Physical activity: Actimeter questionnaire. Multidimensional Fatigue Inventory (General/physical fatigue sub-scale)

Psychosocial: POMS (vigour, anxiety and depression sub-scale); SF-12; menopause-specific QoL questionnaire; Brief Pain Inventory; Inventory of Recent Life Experiences for Cancer Patients; Subjective Appraisal Rating Scale; Coping with Health \& injury Problems questionnaire

Notes

\section{Risk of bias}

\begin{tabular}{|c|c|c|}
\hline Bias & Authors' judgement & Support for judgement \\
\hline $\begin{array}{l}\text { Random sequence genera- } \\
\text { tion (selection bias) }\end{array}$ & Low risk & RCT "computer generated" \\
\hline $\begin{array}{l}\text { Allocation concealment } \\
\text { (selection bias) }\end{array}$ & Low risk & $\begin{array}{l}\text { "Randomly assigned .... using sealed envelopes, which were concealed to both } \\
\text { kinesiologist and patient." }\end{array}$ \\
\hline $\begin{array}{l}\text { Blinding (performance } \\
\text { bias and detection bias) } \\
\text { All outcomes }\end{array}$ & Unclear risk & Not mentioned \\
\hline
\end{tabular}

Incomplete outcome data Low risk Loss to follow-up: numbers and reasons given in flow-chart
(attrition bias)

All outcomes

Selective reporting (re- Low risk All outcomes reported in results
porting bias)

Other bias Low risk

Giesler 2005

\begin{tabular}{|c|c|}
\hline Methods & RCT \\
\hline \multirow[t]{5}{*}{ Participants } & 99 participants (I: 48/C: 51 ) \\
\hline & Cancer sites: prostate $100 \%$ \\
\hline & Mean age: (63.8 years) \\
\hline & Post-treatment: after conclusion of treatment \\
\hline & Country: USA \\
\hline \multirow[t]{2}{*}{ Interventions } & $\begin{array}{l}\text { A computer-assisted intervention designed to improve the QoL of the patient/spouse dyad during the } \\
\text { first year after treatment }\end{array}$ \\
\hline & Contact and duration: 6 contacts ( 1 per month); 2 in person +4 by telephone \\
\hline
\end{tabular}


Physical component: physical strategies provided to deal with identified QoL problems, e.g. exercise prescribed for fatigue, anxiety or symptom distress

Psychosocial component: psychoeducational strategies tailored to eliminate or reduce the impact of identified problems

Assessed at: BL, 4 months, 7 months, 12 months post-treatment
Physical: Prostate Cancer QoL instrument (PCQoL), SF-36
Psychosocial: Prostate Cancer QoL instrument (PCQoL), CES-D, Spanier Dyadic Adjustment Scale (DAS),
SF-36

Notes

\section{Risk of bias}

\begin{tabular}{|c|c|c|}
\hline Bias & Authors' judgement & Support for judgement \\
\hline $\begin{array}{l}\text { Random sequence genera- } \\
\text { tion (selection bias) }\end{array}$ & Unclear risk & $\mathrm{RCT}$ - sequence generation not mentioned \\
\hline $\begin{array}{l}\text { Allocation concealment } \\
\text { (selection bias) }\end{array}$ & Unclear risk & Not mentioned \\
\hline $\begin{array}{l}\text { Blinding (performance } \\
\text { bias and detection bias) } \\
\text { All outcomes }\end{array}$ & Low risk & "Interviewers were blind to the group assignment." \\
\hline $\begin{array}{l}\text { Incomplete outcome data } \\
\text { (attrition bias) } \\
\text { All outcomes }\end{array}$ & Low risk & Loss to follow-up: numbers and reasons reported in text \\
\hline $\begin{array}{l}\text { Selective reporting (re- } \\
\text { porting bias) }\end{array}$ & Low risk & All outcomes reported in results \\
\hline Other bias & High risk & ITT not mentioned \\
\hline
\end{tabular}

\section{Lepore 1999}

\begin{tabular}{ll}
\hline Methods & RCT \\
\hline Participants & 24 participants (I: $12 / C: 12)$ \\
& Cancer sites: prostate $100 \%$ \\
& Mean age: not available \\
& Post-treatment: recruited "after their cancer treatment" \\
& Country: USA \\
& $\begin{array}{l}\text { A psycho-educational support group with emphasis on education, skills training and facilitated discus- } \\
\text { sion to provide emotional support and affect QoL }\end{array}$ \\
Contact and duration: 6 weekly group meetings (40-minute lecture + 20-minute question and answer \\
session + 45 minutes of facilitated peer discussion) \\
Physical component: 1 session on "cancer, diet and exercise"
\end{tabular}


Lepore 1999 (Continued)

Psychosocial component: sessions on managing physical side effects; relaxation and stress management; communication and intimacy; follow-up care and health promotion

\begin{tabular}{|c|c|c|}
\hline Outcomes & \multirow{3}{*}{\multicolumn{2}{|c|}{$\begin{array}{l}\text { Assessed at: } 2 \text { weeks post-intervention } \\
\text { Physical: SF-36 physical function sub-scales } \\
\text { Psychosocial: SF-36 mental function sub-scales, Lepore's Social Conflict scale, Impact of Events scale, } \\
\text { self efficacy, UCLA Social Support scale }\end{array}$}} \\
\hline & & \\
\hline & & \\
\hline Notes & \multicolumn{2}{|c|}{ SF-36 results poorly presented - specific mean values or SD not available } \\
\hline \multicolumn{3}{|l|}{ Risk of bias } \\
\hline Bias & Authors' judgement & Support for judgement \\
\hline $\begin{array}{l}\text { Random sequence genera- } \\
\text { tion (selection bias) }\end{array}$ & Unclear risk & $\mathrm{RCT}$ - sequence generation not mentioned \\
\hline $\begin{array}{l}\text { Allocation concealment } \\
\text { (selection bias) }\end{array}$ & Unclear risk & Not mentioned \\
\hline $\begin{array}{l}\text { Blinding (performance } \\
\text { bias and detection bias) } \\
\text { All outcomes }\end{array}$ & Unclear risk & Not mentioned \\
\hline $\begin{array}{l}\text { Incomplete outcome data } \\
\text { (attrition bias) } \\
\text { All outcomes }\end{array}$ & Low risk & "No attrition" \\
\hline $\begin{array}{l}\text { Selective reporting (re- } \\
\text { porting bias) }\end{array}$ & Low risk & All outcomes were reported in results section \\
\hline Other bias & High risk & Small numbers recruited (24) - no sample size calculation \\
\hline & & ITT not mentioned \\
\hline
\end{tabular}

May 2008a

\begin{tabular}{ll}
\hline Methods & Randomised controlled trial \\
& Analyses based on intention-to-treat \\
& Loss to follow-up: numbers and reasons given in flow-chart \\
& 147 participants (I: $76 / \mathrm{C}: 71)$ \\
& Cancer sites: breast 82 (55.8\%) (I: 48/C: 34$)$; haematological $23(16.6 \%)(\mathrm{I}: 15 / \mathrm{C}: 8)$; gynaecological 17 \\
& $(11.6 \%)(\mathrm{I}: 6 / \mathrm{C}: 15.5) ;$ urological $9(5.5 \%)(\mathrm{I}: 3 / \mathrm{C}: 6)$; other $16(10.9 \%)(\mathrm{I}: 4 / \mathrm{C}: 12)$ \\
& Mean age: 48.8 (I: 47.8/C: 49.9$)$ \\
& Post-treatment: at least 3 months since last treatment \\
& Country: Netherlands
\end{tabular}

Interventions

A combined extensive, supervised exercise programme with a cognitive-behavioural intervention, aimed at solving cancer-related problems that limit patients being physically active in everyday life 
May 2008a (Continued)

Contact and duration: 12 -week supervised programme

Physical component: twice weekly for 2 hours per session. Sessions included bicycle training (30 minutes), muscle strength training (30 minutes), group sport (60 minutes). From week 6 , a home-walking programme was commenced.

Psychosocial component: CBT training once a week, 2 hours per session. Aimed at training self management skills to solve personal problems related to physical and psychosocial consequences of cancer.

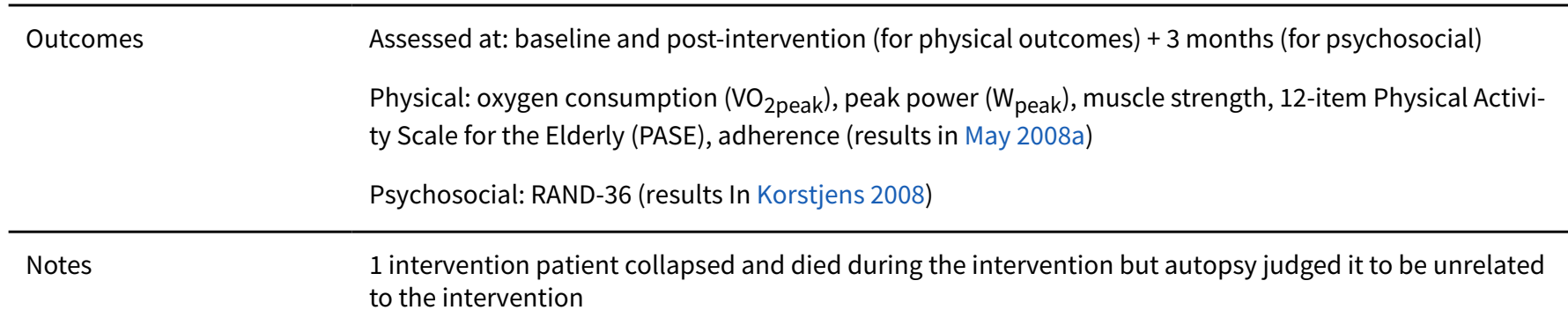

\section{Risk of bias}

\begin{tabular}{|c|c|c|}
\hline Bias & Authors' judgement & Support for judgement \\
\hline $\begin{array}{l}\text { Random sequence genera- } \\
\text { tion (selection bias) }\end{array}$ & Low risk & $\mathrm{RCT}$ "randomisation at group level .... using a randomisation list" \\
\hline $\begin{array}{l}\text { Allocation concealment } \\
\text { (selection bias) }\end{array}$ & Low risk & Randomised by "an independent researcher" \\
\hline $\begin{array}{l}\text { Blinding (performance } \\
\text { bias and detection bias) } \\
\text { All outcomes }\end{array}$ & Unclear risk & Not mentioned \\
\hline $\begin{array}{l}\text { Incomplete outcome data } \\
\text { (attrition bias) } \\
\text { All outcomes }\end{array}$ & Low risk & Loss to follow-up: numbers and reasons given in flow-chart \\
\hline $\begin{array}{l}\text { Selective reporting (re- } \\
\text { porting bias) }\end{array}$ & Low risk & $\begin{array}{l}\text { All outcomes reported in results; N.B. physical outcomes in May 2008a, psy- } \\
\text { chosocial outcomes in Korstjens } 2008\end{array}$ \\
\hline Other bias & Low risk & None identified \\
\hline
\end{tabular}

\section{Rogers 2009}

\begin{tabular}{ll}
\hline Methods & Randomised controlled trial \\
& Intention-to-treat analysis used \\
& Loss to follow-up: numbers in flow-chart; reasons in text \\
\hline Participants & 41 female participants (intervention: $21 / \mathrm{C}: 20)$ \\
& Cancer site: breast $100 \%$ \\
& Mean age: I: 52 years/C: 54 years \\
& Post-treatment: all patients had completed treatment and were receiving hormone therapy for the du- \\
ration of the study (8 months)
\end{tabular}


Rogers 2009 (Continued)

\section{Country: USA}

Interventions

The Better Exercise Adherence after Treatment for cancer (BEAT) programme. A 12-week physical activity behaviour change intervention which aimed to encourage participants to engage in 150 minutes of moderate exercise (walking) per week. Control participants were provided with written materials from the American Cancer Society but were not given specific instructions regarding physical activity.

Contact and duration: intervention participants received 12 supervised physical activity sessions, 6 discussion group sessions and 3 individual counselling sessions

Physical component: 12 individual supervised exercise sessions; 40 home-based exercise sessions; 3 face-to-face update counselling sessions from an exercise specialist

Psychosocial component: intervention participants attended 6 group discussion sessions with a clinical psychologist who discussed a range of topics including: stress management, exercise barriers and behaviour modification

Assessed at: BL and post intervention (3 months)
Physical: objective activity monitoring using: an accelerometer; submaximal treadmill test; back and
leg extension strength using a dynamo-meter; BMl; and waist and hip circumference
Self reported physical activity measured (Godin Leisure-Time Exercise Questionnaire)
Psychosocial: motivation to change (self efficacy and stages of exercise change questionnaire); quality
of life (FACT-B) which includes an emotional well-being scale

Notes

\section{Risk of bias}

\begin{tabular}{lll}
\hline Bias & Authors' judgement & Support for judgement \\
\hline $\begin{array}{l}\text { Random sequence genera- } \\
\text { tion (selection bias) }\end{array}$ & Low risk & $\begin{array}{l}\text { Computer-generated random assignment lists were kept in sealed envelopes } \\
\text { to ensure study personnel could not influence allocation }\end{array}$ \\
\hline $\begin{array}{l}\text { Allocation concealment } \\
\text { (selection bias) }\end{array}$ & Unclear risk & $\begin{array}{l}\text { Due to the nature of the intervention, participants were aware of which inter- } \\
\text { vention was received. Professional staff who undertook objective physical as- } \\
\text { sessments may also have been aware of which participants received the inter- } \\
\text { vention. }\end{array}$
\end{tabular}

\begin{tabular}{lll}
\hline $\begin{array}{l}\text { Blinding (performance } \\
\text { bias and detection bias) } \\
\text { All outcomes }\end{array}$ & High risk & $\begin{array}{l}\text { It was not possible to blind participants to the intervention or control group } \\
\text { nor was it possible to blind professionals who completed the objective physi- } \\
\text { cal measures }\end{array}$ \\
\hline
\end{tabular}

$\begin{array}{ll}\begin{array}{l}\text { Incomplete outcome data } \\ \text { (attrition bias) }\end{array} & \text { Low risk } \\ \text { All outcomes } & \text { Loss to follow-up: attrition following randomisation was low (3/41, 7\%) across } \\ \end{array}$

All outcomes

Selective reporting (re- Unclear risk All outcomes reported in results

porting bias)

Other bias Unclear risk None identified

BL: baseline

BMI: body mass index

BPI: Brief Pain Inventory - short form

C: control

CBT: cognitive behavioural therapy

CES-D: Center for Epidemiologic Studies Depression Scale 
EORTC: European Organisation for Research and Treatment of Cancer

FACT: Functional Assessment of Cancer Therapy

HADS: Hospital Anxiety and Depression Scale

I: intervention

ITT: intention-to-treat

MCS: Mental Component Summary (SF-36)

MI: motivational interviewing

QoL: quality of life

PCS: Physical Component Summary (SF-36)

POMS: Profile of Mood States

PSA: prostate-specific antigen

$\mathrm{RCT}$ : randomised controlled trial

SD: standard deviation

STAI: State-Trait Anxiety Inventory

Characteristics of excluded studies [ordered by study ID]

\begin{tabular}{|c|c|}
\hline Study & Reason for exclusion \\
\hline Berglund 1994 & Did not use established validated physical outcome measures \\
\hline Bloom 2008 & Did not use established validated psychosocial outcome measures \\
\hline Cain 1986 & Did not use established validated physical outcome measures \\
\hline Cho 2006 & Did not use established validated psychosocial outcome measures \\
\hline Courneya 2003 & High percentage of participants receiving primary active treatment regime during the study \\
\hline Cunningham 1989 & High percentage of participants receiving primary active treatment regime during the study \\
\hline Fan 2006 & High percentage of participants receiving primary active treatment regime during the study \\
\hline Hartmann 2007 & $\begin{array}{l}\text { Multidimensional rehabilitation delivered to both intervention and control groups, only the timing } \\
\text { of the rehabilitation programme was tested in this study }\end{array}$ \\
\hline Heim 2007 & $\begin{array}{l}\text { Intervention group received additional physical component but no additional psychosocial com- } \\
\text { ponent to standard inpatient rehabilitation group }\end{array}$ \\
\hline Johansson 2008 & High percentage of participants receiving primary active treatment regime during the study \\
\hline van Weert 2005 & $\begin{array}{l}\text { Although the groups were randomised } 80 \% \text { of the control group opted to attend the full } 15 \text {-week } \\
\text { programme }\end{array}$ \\
\hline Zhang Tong 2005 & Participants receiving primary active treatment regime during the study \\
\hline
\end{tabular}

\section{DATA AND ANALYSES}


Comparison 1. Physical

\begin{tabular}{lllll}
\hline Outcome or subgroup title & No. of studies & $\begin{array}{l}\text { No. of partici- } \\
\text { pants }\end{array}$ & Statistical method & Effect size \\
\hline 1 SF-36 Physical Component Score & 4 & 392 & $\begin{array}{l}\text { Mean Difference (IV, Random, } \\
95 \% \text { Cl) }\end{array}$ & $1.79[-0.82,4.39]$ \\
\hline
\end{tabular}

Analysis 1.1. Comparison 1 Physical, Outcome 1 SF-36 Physical Component Score.

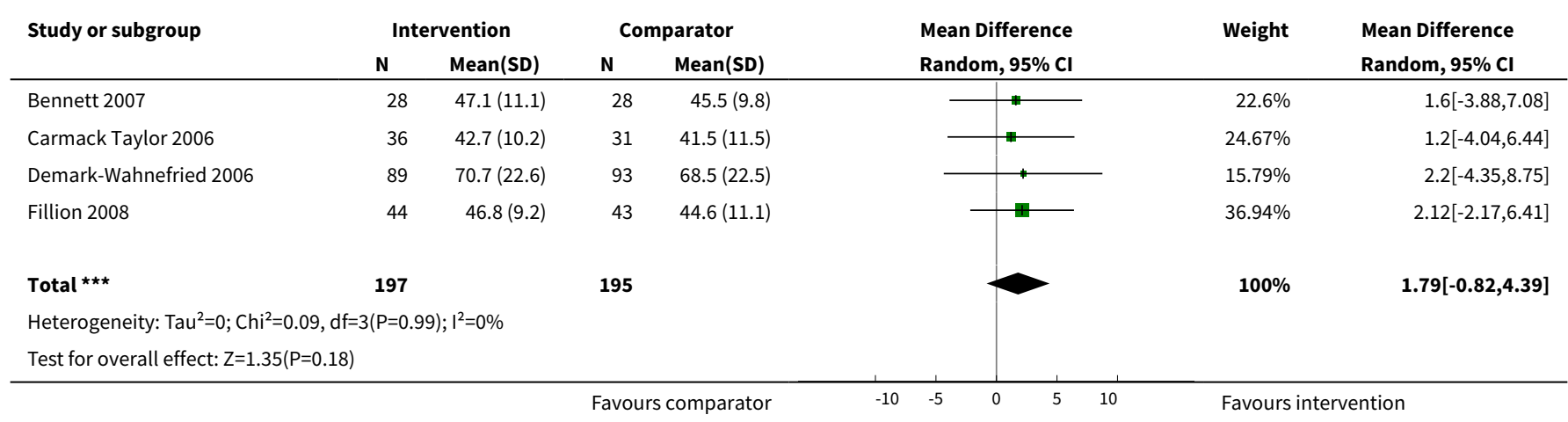

\section{Comparison 2. Psychosocial}

\begin{tabular}{lllll}
\hline Outcome or subgroup title & No. of studies & $\begin{array}{l}\text { No. of partici- } \\
\text { pants }\end{array}$ & Statistical method & Effect size \\
\hline $\begin{array}{l}1 \text { SF-36 Mental Component Summa- } \\
\text { ry }\end{array}$ & 3 & 200 & $\begin{array}{l}\text { Mean Difference (IV, Random, } \\
95 \% \mathrm{Cl})\end{array}$ & $-1.11[-7.34,5.13]$ \\
\hline
\end{tabular}

\section{Analysis 2.1. Comparison 2 Psychosocial, Outcome 1 SF-36 Mental Component Summary.}

\begin{tabular}{|c|c|c|c|c|c|c|c|c|}
\hline \multirow{3}{*}{$\begin{array}{l}\text { Study or subgroup } \\
\text { Bennett } 2007\end{array}$} & \multicolumn{2}{|c|}{ Intervention } & \multicolumn{2}{|c|}{ Comparator } & \multirow{2}{*}{\multicolumn{2}{|c|}{$\begin{array}{l}\text { Mean Difference } \\
\text { Random, } 95 \% \mathrm{CI}\end{array}$}} & \multirow[t]{2}{*}{ Weight } & \multirow{2}{*}{$\begin{array}{l}\text { Mean Difference } \\
\text { Random, } 95 \% \mathrm{Cl}\end{array}$} \\
\hline & \multirow{2}{*}{$\frac{\mathbf{N}}{20}$} & \multirow{2}{*}{$\frac{\text { Mean(SD) }}{44.4(8.2)}$} & \multirow{2}{*}{$\frac{\mathbf{N}}{26}$} & \multirow{2}{*}{$\frac{\operatorname{Mean}(\text { SD) }}{51.7(6)}$} & & & & \\
\hline & & & & & —— & & $32.79 \%$ & $-7.26[-11.54,-2.98]$ \\
\hline Carmack Taylor 2006 & 36 & $53.7(6.8)$ & 31 & $53.4(10.4)$ & & + & $32.79 \%$ & $0.3[-3.98,4.58]$ \\
\hline Fillion 2008 & 44 & $51.4(7.6)$ & 43 & $48(9.3)$ & & $\Psi$ & $34.42 \%$ & $3.42[-0.15,6.99]$ \\
\hline 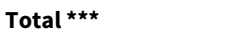 & 100 & & 100 & & & & $100 \%$ & $-1.11[-7.34,5.13]$ \\
\hline \multicolumn{3}{|c|}{ Test for overall effect: $\mathrm{Z}=0.35(\mathrm{P}=0.73)$} & & & & & & \\
\hline
\end{tabular}




\section{APPENDICES}

\section{Appendix 1. Search strategy \\ CENTRAL}

\#1 MeSH descriptor Neoplasms explode all trees

\#2 cancer $^{\star}$ or neoplasm* or carcinoma* or malignan* or tumor ${ }^{\star}$ or tumour ${ }^{\star}$

\#3 (\#1 OR \#2)

\#4 MeSH descriptor Rehabilitation explode all trees

\#5 rehab* near/2 (program* or multidimension*)

\#6 MeSH descriptor Self Care explode all trees

\#7 MeSH descriptor Self-Help Groups explode all trees

\#8 self near/2 (care or manage*)

\#9 selfcare or selfmanage*

\#10 selfhelp or self-help

\#11 MeSH descriptor Social Support explode all trees

\#12 social next support

\#13 support near/2 group*

\#14 group* near/2 (therap* or coping)

\#15 MeSH descriptor Counseling explode all trees

\#16 counsel $^{\star}$

\#17 MeSH descriptor Psychotherapy explode all trees

\#18 (psychosocial or psychological) next (therap* or intervention* or support ${ }^{\star}$ )

\#19 psychotherap*

\#20 (cognitive or behavior or behaviour) next therap*

\#21 MeSH descriptor Relaxation Therapy, this term only

\#22 relax $^{\star}$ near/2 (technique* or train*)

\#23 MeSH descriptor Patient Education as Topic explode all trees

\#24 educat* $^{\star}$ near/2 (intervention* or therap* or patient ${ }^{\star}$ )

\#25 MeSH descriptor Social Work explode all trees

\#26 social next work*

\#27 MeSH descriptor Dietary Services explode all trees

\#28 MeSH descriptor Dietary Supplements explode all trees

\#29 MeSH descriptor Nutritional Sciences explode all trees

\#30 diet* or nutrition* or (healthy next eating)

\#31 MeSH descriptor Exercise explode all trees

\#32 exercis*

\#33 MeSH descriptor Physical Therapy Modalities explode all trees

\#34 physical next (modalit* or therap ${ }^{\star}$ )

\#35 physiotherap*

\#36 acupuncture or massage

\#37 MeSH descriptor Respiratory Therapy explode all trees

\#38 respiratory next therap*

\#39 MeSH descriptor Urinary Incontinence explode all trees

\#40 incontinen ${ }^{\star}$ near/2 train*

\#41 MeSH descriptor Language Therapy explode all trees

\#42 (speech or language) near/2 therap*

\#43 MeSH descriptor Occupational Therapy explode all trees

\#44 occupational next therap*

\#45 (\#4 OR \#5 OR \#6 OR \#7 OR \#8 OR \#9 OR \#10 OR \#11 OR \#12 OR \#13 OR \#14 OR \#15 OR \#16 OR \#17 OR \#18 OR \#19 OR \#20 OR \#21 OR

\#22 OR \#23 OR \#24 OR \#25 OR \#26 OR \#27 OR \#28 OR \#29 OR \#30 OR \#31 OR \#32 OR \#33 OR \#34 OR \#35 OR \#36 OR \#37 OR \#38 OR \#39 OR \#40 OR \#41 OR \#42 OR \#43 OR \#44)

\#46 (\#3 AND \#45)

\section{MEDLINE}
1. exp Neoplasms/
2. cancer $^{\star} . \mathrm{mp}$.
3. neoplasm.mp.
4. exp Carcinoma/
5. carcinoma*.mp.
6. malignan*.mp. 
7. exp Neoplasms/rh

8. tumo\# ${ }^{\star}$.mp.

9. (cancer adj patient $\left.{ }^{\star}\right)$.mp.

10. 1 or 2 or 3 or 4 or 5 or 6 or 7 or 8 or 9

11. exp Rehabilitation/

12. (rehab* adj program*).mp.

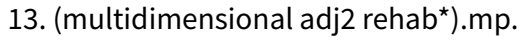

14. Self Care/

15. (self adj care adj support adj program $\left.{ }^{\star}\right)$.mp.

16. (self adj management adj (program ${ }^{\star}$ or training $\left.{ }^{\star}\right)$ ).mp.

17. Self-Help Groups/

18. (self adj help adj group ${ }^{\star}$ ).mp.

19. (selfhelp adj group ${ }^{\star}$ ).mp.

20. social support/

21. (social adj support adj intervention*).mp.

22. (support adj group*).mp.

23. (group adj support ${ }^{\star}$ ).mp.

24. exp Psychotherapy, Group/

25. (group adj therap $\left.{ }^{\star}\right) \cdot \mathrm{mp}$.

26. (group adj coping*).mp.

27. exp Counseling/

28. counsel\#ing ${ }^{\star} \cdot \mathrm{mp}$.

29. exp Psychotherapy/

30. psychotherap*.mp.

31. (psychosocial adj therap $\left.{ }^{\star}\right) \cdot m p$.

32. (psychological adj intervention $\left.{ }^{\star}\right) \cdot m p$.

33. (psychosocial adj intervention ${ }^{\star}$ ).mp.

34. (psychological adj support $\left.{ }^{\star}\right) \cdot m p$.

35. (psychosocial adj support ${ }^{\star}$ ).mp.

36. Relaxation Therapy/

37. (relaxation adj (technique* or training*)).mp.

38. exp Patient Education as Topic/

39. (patient adj education*).mp.

40. (educational adj intervention $\left.{ }^{\star}\right) \cdot m p$.

41. (educational adj therap*).mp.

42. Cognitive Therapy/

43. (cognitive adj therap $\left.{ }^{\star}\right) \cdot m p$.

44. (cognitive adj psychotherapy).mp.

45. (cognitive adj behavio\#r adj therap ${ }^{\star}$ ).mp.

46. (behavio\#r adj therap*).mp.

47. exp Behavior Therapy/

48. exp Social Work/

49. ( social adj work $\left.{ }^{*}\right)$.mp.

50. exp Dietary Services/

51. (dietary adj service*).mp.

52. exp Nutritional Sciences/

53. (dietary adj regime*).mp.

54. (dietary adj composition $\left.{ }^{\star}\right)$.mp.

55. nutrition ${ }^{\star} . \mathrm{mp}$.

56. diet $^{\star} . \mathrm{mp}$.

57. (dietary adj supplement ${ }^{\star}$ ).mp.

58. exp Dietary Supplements/

59. (healthy adj eating*).mp.

60. exp Exercise/

61. (physical adj exercise $\left.{ }^{\star}\right) . m p$.

62. exp Physical Therapy Modalities/

63. (physical adj (modalit ${ }^{\star}$ or therap $\left.\left.{ }^{\star}\right)\right) . m p$.

64. physiotherap*.mp.

65. exp Respiratory Therapy/

66. (respiratory adj therap $\left.{ }^{\star}\right) . m p$.

67. exp Urinary Incontinence/

68. (incontinence adj training ${ }^{\star}$ ).mp.

Multidimensional rehabilitation programmes for adult cancer survivors (Review) 
69. exp Acupuncture/

70. acupunctur*.mp.

71. exp Massage/

72. massage ${ }^{\star} . \mathrm{mp}$.

73. exp Language Therapy/

74. (speech adj2 language adj therap $\left.{ }^{\star}\right)$.mp.

75. exp Occupational Therapy/

76. (occupational adj therap*).mp. 77.11 or 12 or 13 or 14 or 15 or 16 or 17 or 18 or 19 or 20 or 21 or 22 or 23 or 24 or 25 or 26 or 27 or 28 or 29 or 30 or 31 or 32 or 33 or 34 or 35 or 36 or 37 or 38 or 39 or 40 or 41 or 42 or 43 or 44 or 45 or 46 or 47 or 48 or 49 or 50 or 51 or 52 or 53 or 54 or 55 or 56 or 57 or 58 or 59 or 60 or 61 or 62 or 63 or 64 or 65 or 66 or 67 or 68 or 69 or 70 or 71 or 72 or 73 or 74 or 75 or 76

78. 10 and 77

79. limit 78 to humans

80. limit 79 to randomized controlled trial

81. Randomized Controlled Trials as Topic/

82.79 and 81

83.80 or 82

\section{EMBASE}

1. exp neoplasm/

2. cancer $^{\star} . \mathrm{mp}$.

3. neoplasm.mp.

4. exp carcinoma/

5. carcinoma*.mp.

6. malignan*.mp.

7. exp neoplasm/rh

8. tumo\# $r^{\star} \cdot \mathrm{mp}$.

9. (cancer adj patient $\left.{ }^{\star}\right) \cdot \mathrm{mp}$.

10. 1 or 2 or 3 or 4 or 5 or 6 or 7 or 8 or 9

11. exp rehabilitation/

12. (rehab* adj program*).mp.

13. (multidimensional adj2 rehab $\left.^{\star}\right)$.mp.

14. self care/

15. (self adj care adj support adj program*).mp.

16. (self adj management adj (program ${ }^{\star}$ or training*)).mp.

17. self help/

18. (self adj help adj group*).mp.

19. (selfhelp adj group $\left.{ }^{\star}\right) . \mathrm{mp}$.

20. social support/

21. (social adj support adj intervention ${ }^{\star}$ ).mp.

22. (support adj group ${ }^{\star}$ ).mp.

23. (group adj support*).mp.

24. exp group therapy/

25. (group adj therap ${ }^{\star}$ ).mp.

26. (group adj coping $\left.{ }^{\star}\right) \cdot m p$.

27. exp counseling/

28. counsel\#ing ${ }^{\star} . \mathrm{mp}$.

29. exp psychotherapy/

30. psychotherap*.mp.

31. (psychosocial adj therap $\left.{ }^{\star}\right) \cdot \mathrm{mp}$.

32. (psychological adj intervention $\left.{ }^{\star}\right) \cdot m p$.

33. (psychosocial adj intervention ${ }^{\star}$ ).mp.

34. (psychological adj support $\left.{ }^{\star}\right)$.mp.

35. (psychosocial adj support*).mp.

36. relaxation training/

37. (relaxation adj (technique* or training $\left.\left.{ }^{\star}\right)\right)$.mp.

38. exp patient education/

39. (patient adj education $\left.{ }^{\star}\right)$.mp.

40. (educational adj intervention*).mp.

41. (educational adj therap*).mp.

42. exp cognitive therapy/

43. (cognitive adj therap ${ }^{\star}$ ).mp. 
44. (cognitive adj psychotherapy).mp.

45. (cognitive adj behavio\#r adj therap ${ }^{\star}$ ).mp.

46. (behavio\#r adj therap*).mp.

47. exp behavior therapy/

48. exp social work/

49. (social adj work $\left.{ }^{\star}\right) \cdot \mathrm{mp}$.

50. dietetics/

51. (dietary adj service*).mp.

52. exp nutritional science/

53. (dietary adj regime*).mp.

54. (dietary adj composition $\left.{ }^{\star}\right)$.mp.

55. nutrition*.mp.

56. diet $^{\star} . \mathrm{mp}$.

57. (dietary adj supplement $\left.{ }^{\star}\right)$.mp.

58. exp diet supplementation/

59. (healthy adj eating $\left.{ }^{\star}\right) \cdot \mathrm{mp}$.

60. exp exercise/

61. (physical adj exercise*).mp.

62. exp physiotherapy/

63. (physical adj (modalit* or therap $\left.\left.{ }^{\star}\right)\right)$.mp.

64. physiotherap*.mp.

65. exp breathing exercise/

66. (respiration adj therap ${ }^{\star}$ ).mp.

67. exp urine incontinence/

68. (incontinence adj training $\left.{ }^{\star}\right) \cdot \mathrm{mp}$.

69. exp acupuncture/

70. acupunctur ${ }^{\star} . \mathrm{mp}$.

71. exp massage/

72. massage ${ }^{\star} . \mathrm{mp}$.

73. exp speech therapy/

74. (speech adj2 language adj therap ${ }^{\star}$ ).mp.

75. exp occupational therapy/

76. (occupational adj therap ${ }^{\star}$ ).mp.

77. 11 or 12 or 13 or 14 or 15 or 16 or 17 or 18 or 19 or 20 or 21 or 22 or 23 or 24 or 25 or 26 or 27 or 28 or 29 or 30 or 31 or 32 or 33 or 34 or 35 or 36 or 37 or 38 or 39 or 40 or 41 or 42 or 43 or 44 or 45 or 46 or 47 or 48 or 49 or 50 or 51 or 52 or 53 or 54 or 55 or 56 or 57 or 58 or 59 or 60 or 61 or 62 or 63 or 64 or 65 or 66 or 67 or 68 or 69 or 70 or 71 or 72 or 73 or 74 or 75 or 76

78. 10 and 77

79. limit 78 to human

80. limit 79 to randomized controlled trial

81. exp controlled clinical trial/

82.79 and 81

83.80 or 82

\section{Psycinfo}

1. exp Neoplasms/

2. (cancer ${ }^{\star}$ or neoplasm ${ }^{\star}$ or malignan* or carcinoma* or tumo\# $\left.{ }^{\star}\right)$.mp.

3. (cancer adj patient $\left.{ }^{\star}\right) \cdot \mathrm{mp}$.

4. 1 or 2 or 3

5. exp Rehabilitation/

6. (rehab* adj program $\left.{ }^{\star}\right) . \mathrm{mp}$.

7. (multidimensional adj rehab*).mp.

8. exp Self Care Skills/

9. (self adj care adj support adj program*).mp.

10. (self adj management adj (program* or training*)).mp.

11. exp Self Help Techniques/

12. (self adj help adj group ${ }^{\star}$ ).mp.

13. (selfhelp adj group ${ }^{\star}$ ).mp.

14. exp Social Support/

15. (social adj support adj intervention*).mp.

16. exp Support Groups/

17. (support adj group $\left.{ }^{\star}\right) \cdot m p$. 
18. exp Group Psychotherapy/

19. (group adj therap $\left.{ }^{\star}\right)$.mp.

20. (group adj coping*).mp.

21. exp Counseling/

22. counsel\#ing*.mp.

23. exp Psychotherapy/

24. psychotherap ${ }^{\star}$.mp.

25. ((psychosocial or psychological) adj (therap* or intervention $\left.\left.{ }^{\star}\right)\right)$.mp.

26. ((psychosocial or psychological) adj support $\left.{ }^{\star}\right) \cdot \mathrm{mp}$.

27. exp Relaxation Therapy/

28. (relaxation adj (technique* or training $\left.\left.{ }^{\star}\right)\right) . \mathrm{mp}$.

29. exp Client Education/

30. ((patient ${ }^{\star}$ or client $\left.^{\star}\right)$ adj education $\left.{ }^{\star}\right) \cdot m p$.

31. (educational adj (intervention* or therap $\left.\left.{ }^{\star}\right)\right) . m p$.

32. exp Cognitive Therapy/

33. exp Cognitive Behavior Therapy/

34. exp Behavior Therapy/

35. (cognitive adj behavio\#r adj therap ${ }^{\star}$ ).mp.

36. (cognitive adj psychotherap*).mp.

37. ((cognitive or behavio\#r) adj therap*).mp.

38. exp Social Casework/

39. ( social adj work $\left.{ }^{\star}\right) \cdot \mathrm{mp}$.

40. exp Nutrition/ or exp Diets/

41. (dietary adj (service ${ }^{\star}$ or regime ${ }^{\star}$ or composition $\left.{ }^{\star}\right)$ ).mp.

42. nutrition ${ }^{\star} . \mathrm{mp}$.

43. diet ${ }^{\star} . \mathrm{mp}$.

44. (dietary adj supplement $\left.{ }^{\star}\right)$.mp.

45. exp Dietary Supplements/

46. (healthy adj eating*).mp.

47. exp Exercise/

48. (physical adj exercise ${ }^{\star}$ ).mp.

49. exp Physical Therapy/

50. physiotherap ${ }^{\star} . \mathrm{mp}$.

51. (respiratory adj therap ${ }^{\star}$ ).mp.

52. exp Urinary Incontinence/

53. (incontinence adj training ${ }^{\star}$ ).mp.

54. exp Acupuncture/

55. acupunctur ${ }^{\star} . \mathrm{mp}$.

56. exp Massage/

57. massage $e^{\star} \cdot \mathrm{mp}$.

58. exp Speech Therapy/

59. exp Language Therapy/

60. (speech adj2 language adj therap $\left.{ }^{\star}\right) . \mathrm{mp}$.

61. exp Occupational Therapy/

62. (occupational adj therap ${ }^{\star}$ ).mp.

63.5 or 6 or 7 or 8 or 9 or 10 or 11 or 12 or 13 or 14 or 15 or 16 or 17 or 18 or 19 or 20 or 21 or 22 or 23 or 24 or 25 or 26 or 27 or 28 or 29 or 30 or 31 or 32 or 33 or 34 or 35 or 36 or 37 or 38 or 39 or 40 or 41 or 42 or 43 or 44 or 45 or 46 or 47 or 48 or 49 or 50 or 51 or 52 or 53 or 54 or 55 or 56 or 57 or 58 or 59 or 60 or 61 or 62

64.4 and 63

65. limit 64 to human

66. exp Clinical Trials/

67. $\left(\right.$ random $^{\star}$ adj clinical ${ }^{\star}$ adj2 trial $\left.{ }^{\star}\right) . m p$.

68.66 or 67

69.65 and 68

\section{CINAHL}




\begin{tabular}{|c|c|}
\hline S66 & S6 and S64 \\
\hline S65 & S6 and S64 \\
\hline S64 & 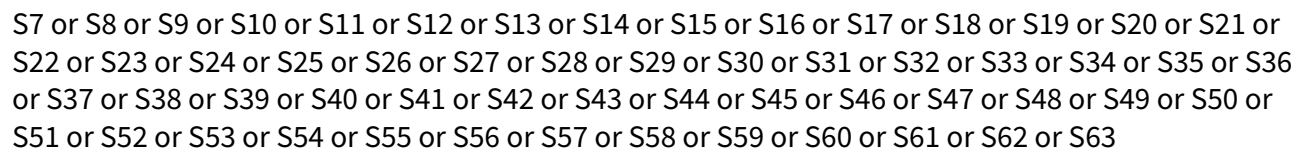 \\
\hline S63 & "occupational therap*" \\
\hline S62 & (MH "Occupational Therapy") \\
\hline S61 & speech n3 therap* \\
\hline S60 & (MH "Language Therapy") \\
\hline S59 & (MH "Speech Therapy+") \\
\hline S58 & massage* $^{\star}$ \\
\hline S57 & (MH "Massage+") \\
\hline S56 & acupunctur* \\
\hline S55 & (MH "Acupuncture+") \\
\hline S54 & "incontinence train*" \\
\hline S53 & (MH "Urinary Incontinence+") \\
\hline S52 & "respiratory therap*" \\
\hline S51 & (MH "Respiratory Therapy+") \\
\hline S50 & physiotherap* \\
\hline S49 & (MH "Physical Therapy+") \\
\hline S48 & "physical exercise*" \\
\hline S47 & (MH "Exercise") \\
\hline S46 & "healthy eat*" \\
\hline S45 & "diet supplement*" \\
\hline S44 & (MH "Dietary Supplements+") \\
\hline S43 & diet $^{\star}$ or nutrition ${ }^{\star}$ \\
\hline S42 & "dietary regime*" or "dietary composition*" \\
\hline S41 & "dietary service*" \\
\hline S40 & (MH "Nutrition Services+") \\
\hline
\end{tabular}


(Continued)

\begin{tabular}{|c|c|}
\hline S39 & "social work" \\
\hline S38 & (MH "Social Work+") \\
\hline S37 & "cognitive psychotherap*" \\
\hline S36 & cognitive $\mathrm{n} 3$ therap* \\
\hline S35 & (MH "Behavior Therapy+") \\
\hline S34 & (MH "Cognitive Therapy") \\
\hline S33 & "educational therap*" \\
\hline S32 & "educational intervention*" \\
\hline S31 & "patient education*" \\
\hline S30 & (MH "Patient Education+") OR (MH "Patient Discharge Education") \\
\hline S29 & "relaxation technique*" or "relaxation therap*" \\
\hline S28 & (MH "Relaxation Techniques+") \\
\hline S27 & "psychological support*" or "psychosocial support" \\
\hline S26 & "psychosocial therap*" or "psychosocial intervention*" or "psychological intervention*" \\
\hline S25 & psychotherap* \\
\hline S24 & (MH "Psychotherapy+") \\
\hline S23 & counsel\#ing \\
\hline S22 & (MH "Counseling+") \\
\hline S21 & "group coping*" \\
\hline S20 & "group therap*" \\
\hline S19 & (MH "Psychotherapy, Group+") \\
\hline S18 & "group support*" \\
\hline S17 & "support group*" \\
\hline S16 & "social support*" \\
\hline S15 & "selfhelp group*" \\
\hline S14 & "self help group \\
\hline S13 & (MH "Support Groups+") \\
\hline S12 & "self management program" or "self management training*" \\
\hline
\end{tabular}


(Continued)

\begin{tabular}{|c|c|}
\hline S11 & "self care support program*" \\
\hline S10 & (MH "Self Care+") \\
\hline S9 & multidimensional n2 rehab* \\
\hline S8 & "rehab* program*" \\
\hline S7 & (MH "Rehabilitation+") \\
\hline S6 & $\mathrm{S} 1$ or $\mathrm{S} 2$ or $\mathrm{S} 3$ or $\mathrm{S} 4$ or $\mathrm{S} 5$ \\
\hline S5 & (MH "Neoplasms+/RH") \\
\hline S4 & "cancer patient" \\
\hline S3 & (MH "Carcinoma+") \\
\hline S2 & cancer $^{\star}$ or neoplasm ${ }^{\star}$ or carcinoma* or malignan* or tumo\#r ${ }^{\star}$ \\
\hline S1 & (MH "Neoplasms+") \\
\hline
\end{tabular}

WHAT'S NEW

\begin{tabular}{lll}
\hline Date & Event & Description \\
\hline 21 September 2016 & Amended & Contact details updated. \\
\hline
\end{tabular}

\section{H I S T O R Y}

Protocol first published: Issue 2, 2009

Review first published: Issue 3, 2013

\begin{tabular}{lll}
\hline Date & Event & Description \\
\hline 11 February 2015 & Amended & Contact details updated. \\
\hline 10 June 2013 & Amended & Contribution of authors updated. \\
\hline
\end{tabular}

\section{CONTRIBUTIONS OF AUTHORS}

MM was funded via a NI Public Health Agency Health and Social Care Research and Development Division Cochrane Review Training Fellowship. DS conducted the final searches and completed the review. DS, MM, MB, AC, CC, KG and MD were involved in the development of the review and in pairs they identified eligible studies, conducted quality assessments of eligible studies and extracted data from the original studies. CC provided statistical advice. SP contributed to the interpretation and critique of the review. MD supervised the conduct and completion of the review. 


\section{DECLARATIONS OF INTEREST}

None

\section{SOURCES OF SUPPORT}

\section{Internal sources}

- No sources of support supplied

\section{External sources}

- R\&D Office NI, UK.

Two-year Cochrane Fellowship

\section{DIFFERENCES BETWEEN PROTOCOLANDREVIEW}

The authors intended to use meta-analysis to statistically pool the results of good-quality studies with homogenous patient groups and similar outcome measures. However, due to the heterogeneity of existing studies both in terms of the MDRP interventions and the outcome measures employed the authors were only able to pool statistically the results of five studies using the SF-36.

Due to the small number of studies and their methodological quality, subgroup analysis was limited to a narrative synthesis. We also hoped to provide a cost-benefit analysis of MDRP programmes but eligible studies did not provide information on their costs.

\section{INDEX TERMS}

\section{Medical Subject Headings (MeSH)}

*Health Status; *Program Evaluation; *Survivors [psychology]; Neoplasms [psychology] [ ${ }^{\star}$ rehabilitation]; Randomized Controlled Trials as Topic; Treatment Outcome

\section{MeSH check words}

Adult; Humans 